\title{
Pockets of Weakness in Strong Institutions: Post-Marketing Regulation, Psychopharmaceutical Drugs, and Medical Autonomy, 1938-1982
}

\section{Herschel Nachlis, Dartmouth College}

\begin{abstract}
A central question in the study of health politics and policy is the degree to which the state can shape American medicine. This long-standing debate began amid early battles over health insurance and continues through the contemporary opioid epidemic. Unlike recent and post-Affordable Care Act claims emphasizing the federal government's strong ability to intervene in healthcare marketplaces, this article supports claims of medicine's autonomy from political intervention, drawing on an extensive analysis of recurrent, halting, and largely unsuccessful efforts to regulate popular psychopharmaceutical drugs from the 1940s through the 1980s. I first develop an account of a "pocket of weakness," the post-marketing pharmaceutical regulatory process, in an otherwise strong institution, the Food and Drug Administration (FDA). I then demonstrate how this regulatory structure, interacting with policymakers' incentives, caused constrained responses, inaction, and drift. Amid concerns about misuse, overuse, abuse, side effects, and addiction, regulators and legislators found it difficult to restrict access to or disincentivize the prescription and consumption of problematic therapeutics, in spite of their varied and repeated regulatory efforts. This elaboration of a pocket of weakness has important theoretical implications for historical institutionalist scholarship that principally focuses on state strength. This account also has substantive implications for scholarship on health politics and policy, mental health treatment, and the political causes of medicalization, and can help explain the opioid epidemic's emergence, potential trajectory, and circumscribed solution set.
\end{abstract}

\section{INTRODUCTION}

From the 1990s through the late 2010s, American policymakers and regulators have attempted to limit the prescription and consumption of many widely used psychopharmaceuticals, including the painkillers central to the contemporary opioid epidemic, as well as a range of sedatives, tranquilizers, stimulants, and antidepressants. But these recent controversies are not the first cases of the American regulatory

Email: Herschel.S.Nachlis@dartmouth.edu

Acknowledgments: For their insights and conversations about these subjects, I am particularly grateful to Chris Achen, Sean Beienburg, Dan Carpenter, Paul Frymer, Sarah Gollust, Peter Hall, Paul Herron, Weiling Huang, John Kastellec, Ken Kersch, Felicia Kornbluh, Anna Kirkland, Marialanna Lee, Alex Levitov, Ted Marmor, Matt McCoy, Richard Morgan, Jim Morone, Allie Norris, Jonathan Oberlander, Marko Radenovic, Chris Ro, Julie Rose, Patrick Schmidt, Rachel Scholz-Bright, Kyle Thomson, Keith Wailoo, Phil Wallach, Jillian Weinberger, Gil Welch, Keith Whittington, and Emily Zackin. I am also grateful to the editors, particularly Tony Chen, and to the anonymous reviewers, for their very helpful comments and suggestions, and to Princeton University's Center for Health and Wellbeing for generous research funding. state confronting such issues. The middle of the twentieth century saw the introduction of a series of psychopharmaceuticals-tranquilizers, sedatives, and stimulants - that became widely popular, used by onesixth to one-quarter of the American public in any given year. These drugs' extensive use and problematic risks and side effects consistently raised concerns about overuse, misuse, abuse, and addiction. In the face of such concerns, because the FDA had already approved these products, they became the objects of post-marketing regulatory scrutiny. From the 1940s through the $1980 \mathrm{~s}$, policymakers and regulators attempted to target these therapeutics with a full menu of post-marketing regulatory instruments.

Amid these largely forgotten efforts, two overarching and opposing views were offered to characterize the relationship between the state and the practice of medicine. These views also reflect recurrent and ongoing disputes. ${ }^{1}$ The first view claims that

1. Paul Starr, The Social Transformation of American Medicine: The Rise of a Sovereign Profession and the Making of a Vast Industry (New York: Basic Books, 1982). 
policymakers and regulators can easily and powerfully infringe on the autonomy of medicine and constrain the medical practices of service providers, product producers, and therapeutic consumers, by swiftly and strongly regulating problematic drugs. As government scientist Mitchell Balter warned in 1973, "the medical system ... lends itself to social control through legislation or regulation." 2 The second and opposing view claims that policymakers and regulators are likely to be largely constrained when trying to affect medical practices, and they are likely to find their efforts halting and ineffective and their abilities to regulate problematic drugs limited. As regulatory official Richard Crout noted in 1978, even aggressive regulation was "unlikely to be a terribly effective strategy for altering physician behavior." 3 These opposing views reflect fundamental tensions in the relationship between the American state and health care system.

Appearing to support the first view-that amid controversies over problematic and popular pharmaceuticals, regulatory efforts should succeed-are two arguments central to current accounts of American health politics and policy. The first argument supporting the regulatory strength view addresses the primary regulatory actor, the FDA. As the chief site of the pharmaceutical regulatory process, the FDA is characterized in Daniel Carpenter's authoritative account as "the world's most powerful regulatory agency," a view widely and rightly shared. ${ }^{4}$ Given such assessments of the relevant regulatory body's strength, it might seem that the agency's efforts to address high-profile public health controversies would be forceful and successful, producing results closer to policy punctuations than issue attention cycles. ${ }^{5}$

Potentially substantiating the regulatory strength view is a second and more general argument about American health politics and policy, one that became pronounced following the 2010 passage of the Affordable Care Act (ACA). In light of the act's

2. Mitchell B. Balter, "An Analysis of Psychotherapeutic Drug Consumption in the United States," in Anglo-American Conference on Drug Abuse, vol. 1, ed. Ronald Alwyne Bowen (London: Royal Society of Medicine, 1973), 58.

3. U.S. Congress, Senate, Committee on Labor and Human Resources, Subcommittee on Health and Scientific Research, Use and Misuse of Benzodiazepines: Hearing before the Subcommittee on Health and Scientific Research of the Committee on Labor and Human Resources, 96th Congress, 1st Sess., 1979, 91.

4. Daniel Carpenter, Reputation and Power: Organizational Image and Pharmaceutical Regulation at the FDA (Princeton, NJ: Princeton University Press, 2010), 22, paraphrasing Philip J. Hilts, Protecting America's Health: The FDA, Business, and One Hundred Years of Regulation (Chapel Hill: University of North Carolina Press, 2004), xiv.

5. Pharmaceutical scholars, regulators, and firms also recognize areas where the FDA's power is less compelling, including post-marketing regulation and pharmacovigilance. But accounts of the pharmaceutical regulatory process and discussions of the FDA principally emphasize regulatory strength and institutional thickening, and primarily examine the implications of the agency's considerable capacity and substantial influence over the drug approval process. Carpenter, Reputation and Power, 585-634. large-scale and multidimensional governmental intervention into the medical sphere, analysts and policymakers have noted the government's strong ability to infringe on medical autonomy by regulating medical practitioner and consumer marketplaces. ${ }^{6}$

These arguments about the FDA's strength and the state's ability to regulate medicine following the ACA are complemented, moreover, by the wealth of work on the American state's expansion. ${ }^{7}$ Such institutional thickening and state strength are further emphasized in health politics and policy scholarship, which focuses on the government's coverage provision through military and veteran health care systems, Medicare, Medicaid, and the Children's Health Insurance Program, and the government's public health provision through the Centers for Disease Control and Prevention, the National Institutes of Health, the Veterans Administration, the Department of Health and Human Services, the Department of Agriculture, the Hill-Burton program, and lesser known but similarly essential bodies like the vaccine court. ${ }^{8}$

6. Scott W. Atlas, "American Health Care: Ignored Facts and Disregarded Options," in Reforming America's Health Care System: The Flawed Vision of ObamaCare, ed. Scott W. Atlas (Stanford: Hoover Institution Press, 2010), 1-22. Leading policymakers like former Congressman and Secretary of the Department of Health and Human Services Tom Price make similar claims, decrying "the intervention of the state and federal government into the practice of medicine." Price entered politics because of his opposition to government intervention into medicine, and his goal as secretary was to dismantle the ACA; Robert Pear, "Tom Price Is Eager to Lead H.H.S., and Reduce Its Clout," New York Times, December 4, 2016.

7. Karen Orren and Stephen Skowronek, The Search for American Political Development (New York: Cambridge University Press, 2004); Stephen Skowronek, Building a New American State: The Expansion of National Administrative Capacities, 1877-1920 (New York: Cambridge University Press, 1982); Richard Bensel, "Southern Leviathan: The Development of Central State Authority in the Confederate States of America," Studies in American Political Development 2 (1987): 68-136; Theda Skocpol, Protecting Soldiers and Mothers: The Political Origins of Social Policy in the United States (Cambridge, MA: Harvard University Press, 1992); William J. Novak, "The Myth of the 'Weak' American State," American Historical Review 113, no. 3 (2008): 752-72; Adam Sheingate, "Why Can't Americans See the State?" The Forum 7, no. 4 (2009): article 1; Daniel P. Carpenter, The Forging of Bureaucratic Autonomy: Reputations, Networks, and Policy Innovation in Executive Agencies, 18621928 (Princeton, NJ: Princeton University Press, 2001); Justin Crowe, Building The Judiciary: Law, Courts, and the Politics of Institutional Development (Princeton, NJ: Princeton University Press, 2012).

8. Anna Kirkland, Vaccine Court: The Law and Politics of Injury (New York: New York University Press, 2016); Ronald Hamowy, Government and Public Health in America (Northampton, MA: Edward Elgar, 2007); William Shonick, Government and Health Services: Government's Role in the Development of U.S. Health Services, 1930-1980 (New York: Oxford University Press, 1995); Stephen P. Strickland, Politics, Science, and Dread Disease: A Short History of United States Medical Research Policy (Cambridge, MA: Harvard University Press, 1972); Carpenter, Reputation and Power, Colin D. Moore, "Innovation without Reputation: How Bureaucrats Saved the Veterans' Health Care System," Perspectives on Politics 13, no. 2 (2015): 32744; Daniel Sledge, Health Divided: Public Health and Individual Medicine in the Making of the Modern American State (Lawrence: University of Kansas Press, 2017); Christy Ford Chapin, Ensuring America's 
An alternative and more traditional view, however, holds that the American state is significantly constrained in its ability to intervene in the medical marketplace. ${ }^{9}$ In analyses that emphasize the ACA's limitations, for example, the act is cast as supporting this latter view, as a "patchwork" and "kludgey" policy "layered" onto and heavily circumscribed by existing policies and political battles. ${ }^{10}$ Further, while the law expands coverage, it does relatively little to affect service delivery or constrain medical costs.

Recent scholarship addressing central features of health politics and policy beyond insurance also supports the position that the government's ability to regulate medicine is limited. Examinations of the medical profession highlight its ability to set prices for its own financial gain with little governmental constraint, and its ability to avoid external impositions on service provision driven by standards of evidencebased medicine, underscoring broader claims about how twentieth-century American medicine's co-evolution with a consumer economy "turned patients into consumers."11 This recent work in

Health: The Public Creation of the Corporate Health Care System (New York: Cambridge University Press, 2015); David G. Smith, The Children's Health Insurance Program: Past and Future (New York: Routledge, 2011); Colleen Grogan and Eric Patashnik, "Between Welfare Medicine and Mainstream Entitlement: Medicaid at the Political Crossroads," Journal of Health Politics, Policy, and Law 28, no. 5 (2003): 821-58; Laura Katz Olson, The Politics of Medicaid (New York: Columbia University Press, 2010); Frank J. Thompson, Medicaid Politics: Federalism, Policy Durability, and Health Reform (Washington, DC: Georgetown University Press, 2012); Shanna Rose, Financing Medicaid: Federalism and the Growth of America's Health Care Safety Net (Ann Arbor: University of Michigan Press, 2013); Jamila Michener, Fragmented Democracy: Medicaid, Federalism, and Unequal Politics (New York: Cambridge University Press, 2018); Jonathan Oberlander, The Political Life of Medicare (Chicago: University of Chicago Press, 2003); Theodore R. Marmor, The Politics of Medicare (New York: Aldine De Gruyter, 2000).

9. Starr, Social Transformation; Monte M. Poen, Harry S. Truman Versus the Medical Lobby: The Genesis of Medicare (Columbia: University of Missouri Press, 1979); Jacob S. Hacker, "The Historical Logic of National Health Insurance: Structure and Sequence in the Development of British, Canadian, and U.S. Medical Policy," Studies in American Political Development 12, no. 1 (1998): 57-130; Jacob S. Hacker, The Road to Nowhere: The Genesis of President Clinton's Plan for Health Security (Princeton, NJ: Princeton University Press, 1997); Theda Skocpol, Boomerang: Health Care Reform and the Turn Against Government (New York: W.W. Norton, 1996); Jill S. Quadango, One Nation, Uninsured: Why the U.S. Has No National Health Insurance (New York: Oxford University Press, 2005); Colin Gordon, Dead on Arrival: The Politics of Health Care in TwentiethCentury America (Princeton, NJ: Princeton University Press, 2003).

10. Theodore Marmor and Jonathan Oberlander, "The Patchwork: Health Reform, American Style," Social Science E Medicine 72, no. 2 (2011): 125-28; Stephen M. Teles, "Kludgeocracy in America," National Affairs 17 (2013): 97-114; Daniel Béland, Philip Rocco, and Alex Waddan, Obamacare Wars: Federalism, State Politics, and the Affordable Care Act (Lawrence: University of Kansas Press, 2016).

11. Miriam J. Laugesen, Fixing Medical Prices: How Physicians Are Paid (Cambridge, MA: Harvard University Press, 2016); Eric M. Patashnik, Alan S. Gerber, and Conor M. Dowling, Unhealthy political science, health policy, and social history provides evidence not of government's capacity for "huge ... intrusion into our health care decisions," as the ACA's critics argue, but rather of classic claims about medical autonomy. ${ }^{12}$

Consistent with the latter view of the state's limited ability to infringe on medical autonomy, I argue that a "pocket of weakness," the post-marketing pharmaceutical regulatory structure, in an otherwise strong institution, the FDA, significantly constrained the strength and efficacy of early efforts to regulate popular and problematic psychopharmaceuticals. Because the FDA's strength evolved to accumulate at the approval stage in the form of the gatekeeping veto, agency regulators and policymakers in Congress and the White House found it highly difficult to restrict access to or disincentivize the prescription and consumption of widely used tranquilizers, sedatives, and stimulants, in spite of their repeated efforts to regulate these products over many decades. The efforts to produce these regulations and strengthen post-marketing regulation were contested and halting, and the regulations achieved were relatively weak and ineffective. This pocket of weakness in the pharmaceutical regulatory structure caused constrained responses, inaction, and drift, impeding policymakers from significantly addressing growing public health concerns, thereby durably diminishing the federal government's authority over medical practices.

This account thus substantiates claims about the constrained ability of the state to regulate medicine. Further, this analysis demonstrates the theoretical centrality of pockets of weakness for identifying the true contours of institutional capacities, elaborates the substantive centrality of a particular site of weakness for understanding the development of psychiatric treatment, and helps explain the emergence and potential trajectory of a large-scale public health crisis, the contemporary opioid epidemic.

To establish these arguments, the article proceeds in five sections. After first situating the argument within the context of scholarship on the American state and American health politics and policy, the second section describes the evolution of the pharmaceutical regulatory structure and the emergence and entrenchment of a pocket of weakness, the post-marketing regulatory process. The third section develops an informal model of the post-marketing regulatory process, describing a sequence of regulatory stages,

Politics: The Battle Over Evidence-Based Medicine (Princeton, NJ: Princeton University Press, 2017); Nancy Tomes, Remaking the American Patient: How Madison Avenue and Modern Medicine Turned Patients into Consumers (Chapel Hill: University of North Carolina Press, 2016). More generally, see Lars Thorup Larsen, "No Third Parties: The Medical Profession Reclaims Authority in DoctorPatient Relationships," Professions E Professionalism 6, no. 2 (2016): $1-14$.

12. Atlas, "American Health Care," 14. 
as well as the actors, potential options, and constraints on these options that emerge from the interaction of this regulatory structure and policymakers' and regulators' political incentives. The fourth section forms the core of the analytic narrative. Through extensive primary source evidence, as well as secondary sources and analysis, aggregated across institutions, cases, and eras, the analysis documents the emergence, controversies over, and repeated efforts to regulate popular and problematic tranquilizers, sedatives, and stimulants from the 1940s through the 1980s. This evidence includes executive and legislative branch reports, data, hearings, rules, press releases, speeches, and other documents; archival material on policy development from the executive and legislative branches; first-person accounts of critical junctures from key actors inside and outside of government; media reporting from national newspapers, national magazines, and local newspapers; epidemiological and survey data; and secondary sources and analysis. The interaction of a pocket of weakness in the regulatory structure with policymakers' and regulators' political incentives, a nexus of "preferences and situations," consistently produced largely halting and ineffective regulations. ${ }^{13}$ The fifth and final section concludes the article, elaborating on the implications of these findings for scholarship on institutional capacities, scholarship on health politics and policy and mental health treatment, and understandings of the contemporary opioid epidemic.

\section{HEALTH POLICY, PHARMACEUTICAL DRUGS, AND THE STUDY OF INSTITUTIONAL CAPACITIES}

In addition to contributing substantively to understandings of pharmaceutical regulation and mental health policy, this account also helps theoretically advance on approaches to understanding the strength and weakness of the American state and its institutions.

Existing scholarship on pharmaceutical regulation and on mental health policy leaves two related and central questions underexplored. Accounts of pharmaceutical regulation warrant additional elaboration on the politics of post-marketing regulation and its consequences for particular categories of disease. Accounts of mental health policy merit elaboration on the political factors affecting transformations in the treatment of mild to moderate psychiatric illnesses. These open questions collectively point toward the need for examining the politics of post-marketing regulation in the case of therapeutics used for mild to moderate mental illnesses.

13. Ira Katznelson and Barry R. Weingast, eds., Preferences and Situations: Points of Intersection between Historical and Rational Choice Institutionalism (New York: Russell Sage Foundation, 2005).
In studies of the political regulation of pharmaceuticals, existing research principally focuses on the FDA's gatekeeping powers. ${ }^{14}$ These accounts, particularly Carpenter's extensive analysis, focus their attention on the agency's accumulation and wielding of its immense pre-market approval power, as well as the emergence and consequences of the deployment of its gatekeeping veto. ${ }^{15}$ Though these accounts note

14. Carpenter, Reputation and Power; Dominique A. Tobbell, Pills, Power, and Policy: The Struggle for Drug Reform in Cold War America and its Consequences (Berkeley: University of California Press, 2012); Arthur A. Daemmrich, Pharmacopolitics: Drug Regulation in the United States and Germany (Chapel Hill: University of North Carolina Press, 2004); Stephen J. Ceccoli, Pill Politics: Drugs and the FDA (Boulder, CO: Lynne Rienner, 2004); Hilts, Protecting America's Health; Lucas Richert, Conservatism, Consumer Choice, and the Food and Drug Administration during the Reagan Era: A Prescription for Scandal (Lanham, MD: Lexington Books, 2014); Harry M. Marks, The Progress of Experiment: Science and Therapeutic Reform in the United States, 1900-1990 (New York: Cambridge University Press, 1997); John P. Swann, "The Evolution of the American Pharmaceutical Industry," Pharmacy in History 37, no. 2 (1995): 76-86; John P. Swann, "FDA and the Practice of Pharmacy: Prescription Drug Regulation before the Durham-Humphry Amendment of 1951," Pharmacy in History 36, no. 2 (1994): 55-70; Peter Temin, Taking Your Medicine: Drug Regulation in the United States (Cambridge. MA: Harvard University Press, 1980). The same is true of trade publications for regulatory participants; see Ira R. Berry and Robert P. Martin, eds., The Pharmaceutical Regulatory Process, 2nd ed. (New York: Informa Healthcare USA, 2008).

15. There is also a growing body of important work on the production, prescription, consumption, and regulation of pharmaceuticals in the twentieth century. These are principally social histories of particular therapeutics or therapeutic categories, and to the extent that these studies do address political factors, they either focus on gatekeeping or do not draw more general conclusions across aggregated pieces of evidence about regulation, health politics and policy, and institutional capacities. Andrea Tone, Age of Anxiety: A History of America's Turbulent Affairs with Tranquilizers (New York: Basic Books, 2008); David Herzberg, Happy Pills in America: From Miltown to Prozac (Baltimore, MD: Johns Hopkins University Press, 2009); Nicolas Rasmussen, On Speed: The Many Lives of Amphetamine (New York: New York University Press, 2008); Robert Bud, Penicillin: Triumph and Tragedy (New York: Oxford University Press, 2007); Jonathan M. Metzl, Prozac on the Couch: Prescribing by Gender in the Era of Wonder Drugs (Durham, NC: Duke University Press, 2003); Mickey C. Smith, A Social History of the Minor Tranquilizers: The Quest for Small Comfort in the Age of Anxiety (New York: Pharmaceutical Products Press, 1991); Charles Medawar, Power and Dependence: Social Audit on the Safety of Medicines (London: Social Audit, 1992); Susan L. Speaker, "From 'Happiness Pills' to 'National Nightmare': Changing Cultural Assessments of Minor Tranquilizers in America, 1955-1980," Journal of the History of Medicine and Allied Sciences 52, no. 3 (1997): 338-76; Elizabeth Siegel Watkins, On The Pill: A Social History of Oral Contraceptives, 1950-1970 (Baltimore, MD: Johns Hopkins University Press, 1998); Jeremy A. Greene, Prescribing by Numbers: Drugs and the Definition of Disease (Baltimore, MD: Johns Hopkins University Press, 2007); Jeremy A. Greene, Generic: The Unbranding of Modern Medicine (Baltimore, MD: Johns Hopkins University Press, 2014); Jerry Avorn, Powerful Medicines: The Benefits, Risks, and Costs of Prescription Drugs (New York: Vintage, 2005); Donald W. Light, ed., The Risks of Prescription Drugs (New York: Columbia University Press, 2010); Jeremy A. Greene, Flurin Condrau, and Elizabeth Siegel Watkins, eds., Therapeutic Revolutions: Pharmaceuticals and Social Change in the Twentieth Century (Chicago: University of Chicago Press, 2016); David Healy, Pharmageddon (Berkeley: University of California Press, 2012); Andrea Tone and Elizabeth Siegel Watkins, eds., Medicating 
that the FDA's post-marketing and pharmacovigilance abilities are less impressive, political scientists and scholars of health politics and policy have given less attention to this strong regulator's most significant site of weakness. ${ }^{16}$ When the regulatory processes relating to the therapeutics analyzed here are addressed, gatekeeping and approval remain the focus, and assessments of the strength of post-marketing regulatory efforts are isolated and inconclusive. ${ }^{17}$

Modern America: Prescription Drugs in History (New York: New York University Press, 2007); Jeremy A. Greene and Elizabeth Siegel Watkins, eds., Prescribed: Writing, Filling, Using, and Abusing the Prescription in Modern America (Baltimore, MD: Johns Hopkins University Press, 2012).

16. While mostly focused on institutional thickening, agency gatekeeping, and organizational reputation in his analysis of the FDA, Carpenter also examines post-marketing regulation, Reputation and Power, 585-634. See also Moshe Maor, "Organizational Reputations and the Observability of Public Warnings in 10 Pharmaceutical Markets," Governance 24, no. 3 (2011): 557-82; Moshe Maor and Raanan Sulitzeanu-Kenan, "The Effect of Salient Reputational Threats on the Pace of FDA Enforcement," Governance 26, no. 1 (2013): 31-61. The many discussions and critiques of post-marketing regulation in the last two decades have almost exclusively occurred within medical communities.

17. Herzberg, Happy Pills; Tone, Age of Anxiety; Smith, Social History; Rasmussen, On Speed; Rufus King, The Drug Hang-Up: America's Fifty-Year Folly (New York: Norton, 1972); Kathleen J. Frydl, The Drug Wars in America, 1940-1973 (New York: Cambridge University Press, 2013); David F. Musto and Pamela Korsmeyer, The Quest for Drug Control: Politics and Federal Policy in a Period of Increasing Substance Abuse, 1963-1981 (New Haven, CT: Yale University Press, 2002); Edward Shorter, Before Prozac: The Troubled History of Mood Disorders in Psychiatry (New York: Oxford University Press, 2009); Edward Shorter, How Everyone Became Depressed: The Rise and Fall of the Nervous Breakdown (New York: Oxford University Press, 2013); Robert Whitaker, Anatomy of an Epidemic: Magic Bullets, Psychiatric Drugs, and the Astonishing Rise of Mental Illness in America (New York: Broadway, 2010); Speaker, "'Happiness Pills"; David Healy, The Creation of Psychopharmacology (Cambridge, MA: Harvard University Press, 2002). For example, Frydl finds that there was "vast retrenchment in prescription medication" and "production and consumption figures plummeted" for a bestselling brand following regulation, while elsewhere Congress created a "loose system of regulation," The Drug Wars in America, 347-48, 273. Shorter meanwhile finds that "the FDA did a lot of muscle flexing, taking on the star drugs of big companies as an exercise in empire building. There is no doubt that today, the FDA towers punishingly over the pharmaceutical industry...in establishing this menacing reputation during the 1960s, the FDA broke a number of eggs." Further, "the agency was able to impose its views on the pharmaceutical industry," and "the concept of the 'tranquilizer'... .was definitely dead." Shorter's central and narrower critique is that the FDA's Drug Efficacy Study Initiative (DESI) program outlawed combination products, including some tranquilizers, that, while not widely popular, were therapeutically successful, Before Prozac, 5, 10, 126, 149. Herzberg, however, finds that major regulatory efforts were "highly contested and partial," and able to pass "in part because of what [they] did not do," Happy Pills, 97, $101,105,113$. Whitaker similarly finds less active and successful regulatory efforts related to one bestselling product class, Anatomy of an Epidemic, 126-47, while Speaker finds overregulation, "'Happiness Pills." On DESI, see Daniel Carpenter, Jeremy Greene, and Susan Moffitt, "The Drug Efficacy Study and Its Manifold Legacies," in FDA in the Twenty-First Century: The Challenges of Regulating Drugs and New Technologies, ed. Holly Fernandez Lynch and I. Glenn Cohen (New York: Columbia University Press, 2015), 306-327.
Research on the politics of mental health, a field whose founders rightly argue has yielded far less study than its subject's substantive significance merits, predominately addresses serious and chronic mental illness and the causes and consequences of de- and re-institutionalization. ${ }^{18}$ This focus on serious and chronic mental illness is reasonable given the severity of such conditions and the government's historical role in treating the mentally ill in state institutions. But focusing primarily on serious and chronic mental illness and psychiatric hospitals also serves to bypass the political factors that have contributed to broader transformations in the treatment and diagnosis of far more widespread mild to moderate psychological health issues. Existing accounts of the expansion of mental health treatment and diagnosis, and attendant processes of medicalization, "by which nonmedical problems become defined and treated as medical problems, usually in terms of illnesses or disorders," instead emphasize the roles of private actors like the psychiatric profession and pharmaceutical firms. ${ }^{19}$ This emphasis on private actors

18. Gerald N. Grob, From Asylum to Community: Mental Health Policy in Modern America (Princeton, NJ: Princeton University Press, 1991); Gerald N. Grob, The Mad Among Us: A History of the Care of America's Mentally Ill (New York: The Free Press, 1994); David Mechanic, Mental Health and Social Policy (Englewood Cliffs, NJ: Prentice Hall, 1989); David A. Rochefort, ed., Handbook on Mental Health Policy in the United States (New York: Greenwood Press, 1989); David A. Rochefort, "Mental Health Policy Inquiry, Its Importance, and Its Rewards," Policy Studies Journal 22, no. 4 (1994): 653-60; Richard G. Frank and Sherry A. Giled, Better But Not Well: Mental Health Policy in the United States Since 1950 (Baltimore, MD: Johns Hopkins University Press, 2006); E. Fuller Torrey, American Psychosis: How the Federal Government Destroyed the Mental Illness Treatment System (New York: Oxford University Press, 2013); Gerald N. Grob and Howard H. Goldman, The Dilemma of Federal Mental Health Policy: Radical Reform or Incremental Change? (New Brunswick, NJ: Rutgers University Press, 2006).

19. Peter Conrad, "Medicalization and Social Control," Annual Review of Sociology 18 (1992): 209; Peter Conrad, The Medicalization of Society: On the Transformation of Human Conditions into Treatable Disorders (Baltimore, MD: Johns Hopkins University Press, 2007); Jonathan M. Metzl and Anna Kirkland, eds., Against Health: How Health Became the New Morality (New York: New York University Press, 2010); Joseph E. Davis and Ana Marta González, eds., To Fix or To Heal: Patient Care, Public Health, and the Limits of Biomedicine (New York: New York University Press, 2016); Allan V. Horwitz, Creating Mental Illness (Chicago: University of Chicago Press, 2002); Allan V. Horwitz and Jerome C. Wakefield, The Loss of Sadness: How Psychiatry Turned Normal Sorrow Into Depressive Disorder (New York: Oxford University Press, 2007); Allan V. Horwitz and Jerome C. Wakefield, All We Have to Fear: Psychiatry's Transformation of Natural Anxieties into Mental Disorders (New York: Oxford University Press, 2012); Edward Shorter, A History of Psychiatry: From the Era of the Asylum to the Age of Prozac (New York: Wiley, 1997); Shorter, Before Prozac; Shorter, How Everyone Became Depressed; Allen Frances, Saving Normal: An Insider's Revolt Against Out-Of-Control Psychiatric Diagnosis, DSM-5, Big Pharma, and the Medicalization of Ordinary Life (New York: William Morrow, 2013); Whitaker, Anatomy of an Epidemic; Gary Greenberg, Manufacturing Depression: The Secret History of a Modern Disease (New York: Simon \& Schuster, 2010); Gary Greenberg, The Book of Woe: The DSM and the Unmaking of Psychiatry (New York: Blue Rider Press, 2013); Christopher Lane, Shyness: How Normal Behavior Became a Sickness (New Haven, CT: 
largely omits political variables. ${ }^{20}$ Examining the postmarketing regulation of widely used psychopharmaceuticals, therefore, draws out the substantive consequences of an essential but less emphasized site of weakness in the regulatory state and healthcare arena, demonstrates its implications for the development of mental health treatment and the practice of medicine, and accounts for underappreciated causes of medicalization by moving beyond private actors to incorporate public policies and politics as contributing factors.

Beyond these substantive contributions, this analysis helps advance theoretical understandings of the strength and weakness of the American state and its institutions. In particular, elaborating an account of a pocket of weakness can draw attention away from the predominant practice of seeking cases of state and institutional strength and toward important instances of weakness.

Particularly among scholars of American political development and institutions, a predominant and successful approach is to seek affirmative cases of the development of political institutions, thickening, and state strength. $^{21}$ This approach emerged in

Yale University Press, 2007); Herb Kutchins and Stuart A. Kirk, Making Us Crazy: DSM: The Psychiatric Bible and the Creation of Mental Disorders (New York: The Free Press, 1997); Hannah S. Decker, The Making of DSM-III: A Diagnostic Manual's Conquest of American Psychiatry (New York: Oxford University Press, 2013); Marcia Angell, The Truth about the Drug Companies: How They Deceive Us and What to Do About It (New York: Random House, 2004); Robert Whitaker and Lisa Cosgrove, Psychiatry Under the Influence: Institutional Corruption, Social Injury, and Prescriptions for Reform (New York: Palgrave Macmillan, 2015). Rick Mayes, Catherine Bagwell, and Jennifer Erkulwater persuasively integrate both political and private factors in their examination of the transformation of childhood attention-deficit/hyperactivity disorder (ADHD) in Medicating Children: ADHD and Pediatric Mental Health (Cambridge, MA: Harvard University Press, 2009).

20. Political analyses of medicalization in other areas include Metzl and Kirkland, Against Health; Anna Kirkland, Fat Rights: Dilemmas of Difference and Personhood (New York: New York University Press, 2008); J. Eric Oliver, Fat Politics: The Real Story Behind America's Obesity Epidemic (New York: Oxford University Press, 2006); Deborah A. Stone, The Disabled State (Philadelphia: Temple University Press, 1984); Theresa Morris, Cut It Out: The C-Section Epidemic in America (New York: New York University Press, 2013); Mayes et al., Medicating Children; Andrew J. Polsky, The Rise of the Therapeutic State (Princeton, NJ: Princeton University Press, 1991); Patricia Strach, Hiding Politics in Plain Sight: Cause Marketing, Corporate Influence, and Breast Cancer Policymaking (New York: Oxford University Press, 2016).

21. Orren and Skowronek, The Search for American Political Development; Adam Sheingate, "Institutional Dynamics and American Political Development," Annual Review of Political Science 17 (2014): 461-77; Richard Valelly, Suzanne Mettler, and Robert Lieberman, eds., The Oxford Handbook of American Political Development (New York: Oxford University Press, 2016); Novak, "The Myth of the 'Weak' American State." This approach also often involves seeking surprising sources of state strength, as in Paul Frymer, Black and Blue: African Americans, the Labor Movement, and the Decline of the Democratic Party (Princeton, NJ: Princeton University Press, 2008); Sean Farhang, The Litigation State: Public Regulation response to the field's initial focus on state weakness, including questions of socialism's relative absence in America. But this corrective and its corresponding emphasis on strength may also go too far in one direction, obscuring areas of weakness. Both strength and weakness are outcomes to be explained that cannot simply be taken for granted, and each deserves empirical and theoretical interrogation. ${ }^{22}$ As such, common approaches primarily emphasizing institutional thickening and strength may potentially yield an incomplete or inaccurate representation of both particular

and Private Lawsuits in the U.S. (Princeton, NJ: Princeton University Press, 2010); Robert C. Lieberman, "Weak State, Strong Policy: Paradoxes of Race Policy in the United States, Great Britain, and France," Studies in American Political Development 16, no. 2 (2002): 138-61; Megan Ming Francis, Civil Rights and the Making of the Modern American State (New York: Cambridge University Press, 2014); Emily Zackin, Looking for Rights in All the Wrong Places: Why State Constitutions Contain America's Positive Rights (Princeton, NJ: Princeton University Press, 2013); R. Shep Melnick, The Transformation of Title IX: Regulating Gender Equality in Education (Washington, DC: Brookings Institution Press, 2018); Paul Nolette, Federalism on Trial: State Attorneys General and National Policymaking in Contemporary America (Lawrence: University of Kansas Press, 2015); Paul Frymer, Building an American Empire: The Era of Territorial and Political Expansion (Princeton, NJ: Princeton University Press, 2017); Chloe N. Thurston, At the Boundaries of Homeownership: Credit, Discrimination, and the American State (New York: Cambridge University Press, 2018); Jonathan Obert, "The Co-Evolution of Public and Private Security in Nineteenth-Century Chicago," Law E Social Inquiry 43, no. 3 (2018): 827-61; Daniel J. Galvin, "Deterring Wage Theft: Alt-Labor, State Politics, and the Policy Determinants of Minimum Wage Compliance," Perspectives on Politics 14, no. 2 (2016): 324-50; Michael Javen Fortner, "The Carceral State and the Crucible of Black Politics: An Urban History of the Rockefeller Drug Laws," Studies in American Political Development 27, no. 1 (2013): 14-35; Andrew S. Kelly, "The Political Development of Scientific Capacity in the United States," Studies in American Political Development 28, no. 1 (2014): 1-25; Ruth Bloch Rubin, Building the Bloc: Intraparty Organization in the U.S. Congress (New York: Cambridge University Press, 2017); Carol Nackenoff, "The Private Roots of American Political Development: The Immigrants' Protective League's 'Friendly and Sympathetic Touch,' 1908-1924," Studies in American Political Development 28, no. 2 (2014): 129-60; Gwendoline M. Alphonso, Polarized Families, Polarized Parties: Contesting Values and Economics in American Politics (Philadelphia: University of Pennsylvania Press, 2018); Brian D. Feinstein and Eric Schickler, "Platforms and Partners: The Civil Rights Realignment Reconsidered," Studies in American Political Development 22, no. 1 (2008): 1-31; Quinn Mulroy, "Approaches to Enforcing the Rights Revolution: Private Civil Rights Litigation and the American Bureaucracy," in The Rights Revolution Revisited: Institutional Perspectives on the Private Enforcement of Civil Rights, ed. Lynda G. Dodd (New York: Cambridge University Press, 2018), 27-45; Daniel Carpenter and Benjamin Schneer, "Party Formation through Petitions: The Whigs and the Bank War of 1832-1834," Studies in American Political Development 29, no. 2 (2015): 213-34; and sources of policy feedback, as described in Paul Pierson, Politics in Time: History, Institutions, and Social Analysis (Princeton, NJ: Princeton University Press, 2004).

22. I thank the editors for their helpful suggestions on emphasizing this point. 
institutions and the overall distribution of the state's capacities. $^{23}$

Similarly, examining mainly clear cases of state building through revision, conversion, and layering can unnecessarily narrow understandings of "durable shifts of governing authority" to cases of positive increases in governmental strength. ${ }^{24}$ Restricting the definition and analysis of "political development" to durable shifts that demonstrate increases in state strength neglects the fact that governing authority can also shift in relation to the private sector in its relative diminishment. ${ }^{25}$ Examining the diminishment of governmental authority only through instances of formal retrenchment, however, which are themselves rare, may likewise yield analytically and theoretically incomplete accounts of the cases and dynamics of shifting governmental authority. ${ }^{26}$

As demonstrated in the analysis that follows, government authority can also durably diminish if its structures allow for increases in private authority without concomitant growth in government capacity, thereby empowering market actors and constraining the state's regulators and policymakers. This typically occurs through both inaction and drift, in which "new or newly intensified social risks" and associated demands for policymaking grow, but policy is "poorly equipped to grapple" with these issues, and does not or is deliberately prevented from keeping pace. ${ }^{27}$

23. These concerns are noted by comparatively oriented historical institutionalists, including Steven Levitsky and Maria Victoria Murillo, "Variation in Institutional Strength," Annual Review of Political Science 12 (2009): 115-33 and Hillel Soifer and Matthias vom Hau, "Unpacking the Strength of the State: The Utility of State Infrastructural Power," Studies in Comparative International Development 43, no. 3-4 (2008): 219-30.

24. Orren and Skowronek, The Search for American Political Development, 123.

25. Jacob S. Hacker and Paul Pierson, Off Center: The Republican Revolution and the Erosion of American Democracy (New Haven, CT: Yale University Press, 2005); Jacob S. Hacker and Paul Pierson, Winner-Take-All Politics: How Washington Made the Rich Richer-and Turned Its Back on the Middle Class (New York: Simon \& Schuster, 2010); David Vogel, The Politics of Precaution: Regulating Health, Safety, and Environmental Risks in Europe and the United States (Princeton, NJ: Princeton University Press, 2012); Jacob S. Hacker, "Privatizing Risk without Privatizing the Welfare State: The Hidden Politics of Social Policy Retrenchment in the United States," American Political Science Review 98, no. 2 (2004): 243-60.

26. Paul Pierson, Dismantling the Welfare State? Reagan, Thatcher, and the Politics of Retrenchment (New York: Cambridge University Press, 1994); Hacker, "Privatizing Risk"; Sarah Staszak, "Institutions, Rulemaking, and the Politics of Judicial Retrenchment," Studies in American Political Development 24, no. 2 (2010): 168-89; Sarah Staszak, No Day in Court: Access to Justice and the Politics of Judicial Retrenchment (New York: Oxford University Press, 2015); Peter Starke, "The Politics of Welfare State Retrenchment: A Literature Review," Social Policy E् Administration 40, no. 1 (2006): 104-20.

27. Hacker, "Privatizing Risk," 246; Jacob S. Hacker, Paul Pierson, and Kathleen Thelen, "Drift and Conversion: Hidden Faces of Institutional Change," in Advances in Comparative-Historical Analysis, ed. James Mahoney and Kathleen Thelen (New York: Cambridge University Press, 2015), 180, 184; Suzanne Mettler, "The Policyscape and the Challenges of Contemporary Politics to Policy Maintenance," Perspectives on Politics 14, no. 2 (2016): 369-90.
The entrenched pocket of weakness described here is an institutional feature that yields both inaction and drift in the face of new demands for regulation. ${ }^{28}$

The concept of pockets of weakness advanced here follows from and expands on analogous concepts developed to explain pockets of expertise in twentieth-century state legislatures. ${ }^{29}$ There, as institutions, leadership, staffing, and committee systems evolved, small islands of expert knowledge emerged and became entrenched over time. While developing somewhat unintentionally and due to policy reforms focused elsewhere, these pockets of legislative expertise wield enormous influence over policymaking, representing yet another surprising source of state strength.

As elaborated below, the FDA's pocket of weakness, its post-marketing regulatory process, also arose largely as a consequence of policymakers' emphasis on other areas, namely, pre-market safety, efficacy, and approval. Like its legislative analogues, this pocket has had important influences on the American policyscape, seriously constraining the government's ability to shape health care practices and limiting the government's ability to infringe on medical autonomy, thereby preserving it. Accordingly, and in contrast, the concept of pockets of weakness offered here serves to draw attention away from strength and clear state building to shifts in governing authority driven by limitations on policymaking and government authority's relative diminishment.

The evidence for the account that follows is drawn from the extensive analysis of primary and secondary materials covering the 1940 s through the 1980 s, which addresses the policymaking efforts of a range of regulators, legislators, and administrations across multiple product categories, institutions, and eras. ${ }^{30}$

28. Here, increased need for regulation followed from concerns about the risks and side effects of new and newly popular psychopharmaceuticals. In the face of these "new or newly intensified social risks" and associated policy needs, a pocket of state weakness, the post-marketing pharmaceutical regulatory process, was "poorly equipped to grapple" with these issues. Moreover, policymakers and regulators could not successfully update policy to keep pace with intensified risks because of this site of weakness's deep historical entrenchment. This entrenchment derived from the co-occurring and recurrent entrenchment of the pre-market approval process's strength, and regulators' and policymakers' associated political incentives. These weak policies remained in place as their context changed in ways that further decreased their effectiveness.

29. Nancy Burns, Laura Evans, Gerald Gamm, and Corrine McConnaughy, "Pockets of Expertise: Institutional Capacity in Twentieth-Century State Legislatures," Studies in American Political Development 22, no. 2 (2008): 229-48.

30. I focus on these earlier and first eras of blockbuster drugs for six reasons: They occurred before the contemporary controversies that many analysts incorrectly identify as deriving from "the first generation of psychotropic drugs," as in Francis Fukuyama, Our Posthuman Future: Consequences of the Biotechnology Revolution (New York: Picador, 2002), 52; they are substantively important but largely overlooked; they are sufficiently temporally distant to have allowed for primary and secondary source evidence to emerge; they allow for the analysis of a range of particular cases 
By elaborating and aggregating this wealth of evidence, the broader patterns and structure of a constrained politics of post-marketing regulation can be observed, demonstrating a recurrent set of difficulties, weaknesses, and limited effects. ${ }^{31}$

Before turning to the narrative, I first explain the emergence and entrenchment of the post-marketing pharmaceutical regulatory process, provide an informal model of this process, and then elaborate on the multi-institutional political incentives that animate its execution.

\section{THE EMERGENCE AND IMPLICATIONS OF A POCKET OF REGULATORY WEAKNESS}

Central features of the American healthcare system demonstrate how early decisions about policy designs affect downstream politics and policymaking. Most clearly, the structure of private health insurance coverage exhibits early policy contingency, adoption of a work-tied and tax-preferred configuration at the critical juncture of World War II, ensuing policy feedback, mobilization, increasing returns, and, ultimately, lock-in and path dependence. This trajectory is essential for understanding American health insurance and for understanding the challenging and perennially circumscribed terrain of potential health care reforms. ${ }^{32}$

The pharmaceutical regulatory structure exhibits a similar dynamic, in which an institutional structure focused on gatekeeping and product approval was established, reinforced, and locked in. From the 1906 publication of Upton Sinclair's The Jungle and the 1906 Pure Food and Drug Act to the 1937 Elixir Sulfanilamide disaster and the 1938 Food, Drug, and Cosmetic Act to the thalidomide crisis of the early 1960s and the 1962 Kefauver-Harris Amendments, major safety scares spurred changes in laws

over time, increasing observations along two critical dimensions that allow for more robust and generalizable inferences about the probabilistic and marginal effects of political institutions, as in Alexander L. George and Andrew Bennett, Case Studies and Theory Development in the Social Sciences (Cambridge, MA: MIT Press, 2005); Stephen G. Brooks and William C. Wohlforth, "From Old Thinking to New Thinking in Qualitative Research," International Security 26, no. 4 (2002): 93-111; they help relocate the timing, origins, and political causes of changes in mental health treatment and medicalization; and they speak to contemporary substantive and theoretical concerns about issues like the opioid epidemic by drawing on cases and evidence from outside of the present context.

31. Of course, the direct counterfactual of no attempted governmental interventions cannot be observed.

32. Hacker, "The Historical Logic of National Health Insurance"; Marmor and Oberlander, "The Patchwork"; Paul Starr, Remedy and Reaction: The Peculiar American Struggle Over Health Care Reform (New Haven, CT: Yale University Press, 2011); Eric M. Patashnik and Julian E. Zelizer, "The Struggle to Remake Politics: Liberal Reform and the Limits of Policy Feedback in the Contemporary American State," Perspectives on Politics 11, no. 4 (2013): $1071-87$. and practices that consistently strengthened pre-market safety and approval procedures. These changes include, for example, the shift from requiring only clinical evidence of safety and efficacy to requiring evidence from multiple double-blind, randomized, placebo-controlled trials. ${ }^{33}$

Critically, over the course of the FDA's development, and with each successive reform, the agency's gatekeeping veto became fixed as the pharmaceutical regulatory process's primary site of governmental intervention. Given the reputational incentives and error preferences of regulators and policymakerswhich followed from public opinion dynamics-with each drug-scare-induced major reform to the pharmaceutical regulatory process, pre-market approval procedures were strengthened. Allowing drugs to enter the market that prove to seriously injure or kill consumers not only harms consumers, but could also undercut regulators' reputations for competence and perceived authority, induce severe punishment from the public and elected officials, and thereby decrease regulators' power. To avoid such errors and their costs, and to sustain their reputations and capabilities, regulatory attention and resources were devoted to a stringent and laborious approval process. During this pre-market approval process, firms spend large amounts of money and time on drug development and testing to demonstrate safety and efficacy, and the FDA devotes considerable resources and time to pre-market review.

Meanwhile, post-marketing regulation emerged as a distant secondary concern, one lacking the attention, resources, and regulatory capacities associated with the gatekeeping veto. This post-marketing weakness emerged largely because the vast resource and temporal costs imposed by the government on firms at the gatekeeping stage represented a fundamental trade-off: Once a drug was finally approved, FDA interference would be limited, and approved products, the firms that marketed and sold them, the doctors that prescribed them, and the consumers that used them would be granted wide legal and conceptual power. $^{34}$

This trade-off yielded a strong pre-market approval process with weak post-marketing regulation, a structure around which most public and private interests oriented their practices, mobilized, and locked in via standard dynamics of policy feedback and path dependence. This division-gatekeeping stringency alongside post-marketing latitude-in the core of

33. Carpenter, Reputation and Power, Daniel P. Carpenter, "The Political Economy of FDA Drug Review: Processing, Politics, and Lessons for Policy," Health Affairs 23, no. 1 (2004): 52-63.

34. Daniel Carpenter, "Reputation, Gatekeeping, and the Politics of Post-Marketing Drug Regulation," Virtual Mentor 8, no. 6 (2006): 403-406; Daniel Carpenter and Michael M. Ting, "The Political Logic of Regulatory Error," Nature Reviews Drug Discovery 4, no. 10 (2005): 819-23. 
the pharmaceutical regulatory structure emerged early on and was deepened with each major reform, making deviation ever more difficult.

Whether or not this focus on gatekeeping is the optimal approach to the "stopping problem" of drug approval, as an empirical matter of institutional evolution, the FDA's gatekeeping strength has been paired with post-approval weakness, and the tools for addressing many problems that emerge after approval are limited. Accordingly, the practice of post-marketing regulation and efforts to update it have remained comparatively difficult, tentative, and ineffective, even when strongly attempted by regulators and legislators.

\section{1. "Restrict Its Use Somehow": An Informal Model of Post-Marketing Regulatory Options}

The post-marketing regulatory decision-making process in these eras can generally be modeled as a sequence of decisions occurring in four stages. ${ }^{35} \mathrm{In}$ the first stage, policymakers, via assorted systems of "pharmacovigilance," had to determine whether new adverse events or safety risks existed for a product already on the market or whether status quo marketing and information-provision procedures insufficiently captured apparent risks. ${ }^{36}$ If no new risks were observed nor procedural shortcomings found in the status quo, a product remained on the market, with its risk profile fully captured by the prescribing and informational regulations already adopted by the agency at its approval stage.

If, instead, new risks or procedural shortcomings were found, policymakers next had to decide whether the available evidence suggested high and severe safety risks to consumers or mild to moderate safety risks. In this second stage, the question was whether observed or anticipated harms were so severe that the product was too dangerous to remain on the market under any conditions. Such cases of severe risk and market removal generally involve the observed or anticipated loss of life or widespread serious harm. Cases of market removal are, however, rare ${ }^{37}$ Given that the long and costly approval process focuses on testing for such consequences, and because a removal both withdraws a likely useful product from sale and admits the

35. This is an inductive and descriptive informal model of the federal post-marketing regulatory process in these eras, drawing on empirical observations. It does not have the features of a formal model or address state and local policy, and the process it describes is emergent, not codified.

36. Arthur Daemmrich and Jeremy Greene, "From Visible Harm to Relative Risk: Centralization and Fragmentation of Pharmacovigilance," in The Fragmentation of U.S. Health Care: Causes and Solutions, ed. Einar Elhauge (New York: Oxford University Press, 2010), 303-24.

37. In most such cases the FDA encourages but does not formally demand removal, and firms almost always comply. agency's dereliction of its chief duty to test for safety at approval, the FDA has preferred to avoid incurring the high reputational and social welfare costs of having firms remove products from market. $^{38}$

Accordingly, most cases of post-approval regulation are less dramatic and involve new product risks or new procedural concerns, but fall short of the major disasters that might cause the agency to seek removal. In these cases, for products that are assessed as mildly to moderately harmful, including, as in the cases here, those seen as overused, misused, abused, and addictive, the choice was less precise than the decision in the second stage. Instead, in this third stage, regulators can decide of a product, in the words of medical historian Harry Marks, to attempt to "restrict its use somehow." ${ }^{39}$ In the third stage, for drugs not safe enough to leave alone but not dangerous enough to remove from market, policymakers can decide to attempt regulation rather than to allow a mildly to moderately harmful product to continue being prescribed based on the now-outdated and "misbranded" risk profile and marketing procedures set at approval.

Once a decision to regulate is made in the third stage, then in the fourth stage, four questions arise: Who can regulate? What regulatory options are available? How easily deployed is each regulatory option? And how effective is each regulatory option likely to be? Two primary sites of regulation existed in the eras examined: one centered on regulators and the FDA and the other centered on legislators and policymakers in Congress and the White House. The FDA could principally attempt to regulate drug labeling and drug advertising or scientifically reassess a drug's risk profile, while Congress and the White House could pursue law enforcement activities against prescribing and use, create new restrictions on drugs, or move drugs into new or higher categories of restriction. ${ }^{40}$

Importantly, across these six regulatory options that were available in the fourth stage, each involved significant difficulties in its deployment and limitations to its efficacy, problems caused by the interaction of the regulatory structure described above and the political incentives described below.

38. Carpenter and Ting, "The Political Logic of Regulatory Error"; Carpenter, "Reputation, Gatekeeping, and the Politics of Post-Marketing Drug Regulation."

39. Harry M. Marks, "Making Risks Visible: The Science, Politics, and Regulation of Adverse Drug Reactions," in Ways of Regulating Drugs in the 19th and 20th Centuries, ed. Jean-Paul Gaudillière and Volker Hess (New York: Palgrave Macmillan, 2013), 104.

40. This is a simplified sequential model, but these strategies may be pursued simultaneously and recursively and by multiple actors. 


\subsection{The Interaction of Regulatory Structure and Political Incentives: Limitations on the Deployment and Efficacy of Post-Marketing Regulatory Tools}

The FDA's primary post-marketing regulatory powers addressed drug labeling and drug advertising. But such information-management tools were indirect and weak instruments for influencing physician behavior, as they only directly addressed the information environment and not medical practice. Likewise, revised informational details in labels and advertisements primarily communicated information to medical professionals, not to consumers. Further, even when attempting to convey information about any new dangers, the agency faced data limitations: Successful collection of reliable and valid data on post-marketing adverse events was expensive, practically cumbersome, and legally difficult-and thus generally lacking. ${ }^{41}$ Accordingly, the FDA's tools related to information management like the regulation of drug labeling and advertising, however aggressively or creatively pursued, were strictly informational and relatively weak. ${ }^{42}$

Agency officials could also scientifically reassess products' risk profiles in efforts to spur adjustments to the regulatory categories under which products were regulated. But the evidentiary standards required for recategorization were high, and administrative efforts to change a popular and profitable drug's status were lengthy, costly, and subject to protracted legal challenges by well-resourced, mobilized, and motivated opponents. ${ }^{43}$

Given that the FDA's regulatory options were limited to these weak tools, regulatory efforts often continued beyond the agency and into Congress and the White House. These policymakers, together with regulators in the FDA and the Drug Enforcement Administration (DEA; and its predecessor, the Bureau of Narcotics and Dangerous Drugs), primarily attempted to pass laws carving out new restrictions and place broad categories of drugs under them. Such efforts to create new restrictions and move drugs under them produced additional substantial hurdles. The barriers to strong statutory pharmaceutical regulation included large-scale special interest mobilization; a regulatory site (Congress) with many pivotal actors, chokepoints, and vetoes; solutions modeled on a set of existing policies addressing illegal drug regulation that were not readily adaptable to the problem of controversial and popular legal

41. Susan Thaul, Drug Safety and Effectiveness: Issues and Action Options after FDA Approval, No. RL32797 (Washington, DC: U.S. Library of Congress, Congressional Research Service, 2005); Daemmrich and Greene, "From Visible Harm to Relative Risk."

42. This era preceded the common use and recognition of controversial black box warnings.

43. Richard Hughes and Robert Brewin, The Tranquilizing of America: Pill Popping and the American Way of Life (New York: Harcourt, Brace, Jovanovich, 1979), 251, 272. products; and electoral incentives motivating policymakers to address drug problems mainly by targeting illegal drugs, the most controversial substances with few defenders, rather than legal drugs with similar problems and many defenders.

A final tool was also available: law enforcement and the direct policing of potentially illegal distribution, purchasing, and consumption. But the enforcementbased approach required considerable resources, and regulatory agents and their political principals did not want to suffer the intensive resource costs of policing. Further, reputation-minded regulators and legislators preferred to avoid what might be seen as policing the private medical treatment and health care practices of their constituents, as government policing of Americans' medicine cabinets could invite considerable public opposition.

Overall, while regulatory efforts in the analysis that follows grew to involve agencies, legislators, and presidents, each available option, and each effort to "restrict its use somehow," faced significant constraints on its deployment and efficacy. The combination of a pocket of weakness in the otherwise strong pharmaceutical regulatory structure and the political incentives of policymakers consistently produced halting and ineffective post-marketing regulation of controversial popular psychopharmaceuticals. Substantively, this combination produced widespread and often problematic prescribing and consumption, and it preserved medical autonomy. Further, it generated a de facto mental health policy privileging pharmaceutical treatments and contributed to the medicalization of distresses that many viewed as ordinary life problems.

\section{REGULATING AMERICA'S FIRST BLOCKBUSTER PSYCHOPHARMACEUTICAL DRUGS}

The American healthcare landscape changed significantly after World War II, involving new programs of large-scale hospital construction, growth in private and public health insurance and health care services, new investments in medical research, and increases in the efficacy and availability of medical therapies, most notably pharmaceutical treatments. For much of the 1950 s, 1960s, and 1970s, the pharmaceutical industry was the first or second most profitable sector of the American economy, and drugs prescribed to treat anxiety and depression, psychic tension, and mild to moderate mental distress-what were generally labeled "neuroses" in contrast to more serious "psychoses"-were the industry's bestselling products. ${ }^{44}$

The conditions the modern drugs treated were not new. In evidence since at least the Book of Job, these

44. Ibid., 252; Milton Silverman and Philip R. Lee, Pills, Profits, and Politics (Berkeley: University of California Press, 1976), 30; Herzberg, Happy Pills, 11, 23; Tone, Age of Anxiety, 154. 
conditions in the nineteenth and early twentieth centuries were called "neurasthenia," "frazzled nerves," and "Americanitis" and are today recognized as mood disorders like anxiety and depression. ${ }^{45}$ What changed in the 1940s and 1950s were the methods, scale, and acceptance of treatments. Legal medical products could for the first time be prescribed with great ease, in large quantities, and at low cost, especially when compared to earlier eras' expensive and involved "rest cures," "work cures," and "insulin comas," or then culturally prominent Freudian psychoanalysis, the actual practice of which was largely restricted to coastal elites. ${ }^{46}$

\section{1. "You Couldn't Have Stopped It": New Drugs, Widespread Prescription, and Recurrent Controversy in the Postwar Marketplace}

The new treatment options that entered the postwar American marketplace took different forms. Stimulants like amphetamines were used to elevate mood and treat lethargy; sedative and hypnotic drugs like barbiturates calmed nerves, relieved stress, and helped with sleep; and the most successful category, minor tranquilizers like benzodiazepines, treated anxiety and psychic tension. ${ }^{47}$ At their height, stimulant prescriptions reached more than 25 million per year. Sedative and hypnotic prescriptions reached approximately 55 million yearly prescriptions, and minor tranquilizers, which partially replaced and were more widely used than barbiturates and amphetamines, reached more than 100 million annual prescriptions. At their heights, psychopharmaceuticals collectively reached approximately 200 million yearly prescriptions in these eras. ${ }^{48}$

45. Robert Burton, The Anatomy of Melancholy (New York: New York Review Classics, 2001), first published 1621, runs well over 1,000 pages.

46. Jonathan Engel, American Therapy: The Rise of Psychotherapy in the United States (New York: Gotham, 2008); Shorter, A History of Psychiatry.

47. In today's marketplace, the amphetamines are most similar to stimulants for ADHD and depression like Adderall and Ritalin; the minor tranquilizers are most similar to antianxiety medications like Xanax and Ativan; and the barbiturates have effects between the antianxiety medications and hypnotic, sedative, and sleep medications like Ambien and Lunesta.

48. Mitchell B. Balter and Jerome Levine, "The Nature and Extent of Psychotropic Drug Usage in the United States," Psychopharmacology Bulletin 5, no. 4 (1969): 3-13; "Tightening the Lid on Legal Drugs," Science News 107, no. 24 (1975): 382; Smith, Social History, 31-32. The U.S. Congress, House, Committee on Interstate and Foreign Commerce, Subcommittee on Public Health and Welfare, Drug Abuse Control Amendments: Hearings before the Subcommittee on Public Health and Welfare of the Committee on Interstate and Foreign Commerce Part One, 91st Congress, 2nd Sess., 1970, 209, 245-46, cites figures closer to 180 million; U.S. Congress, Senate, Select Committee on Small Business, Subcommittee on Monopoly, Advertising of Proprietary Medicines: Hearings Before the Subcommittee on Monopoly of the Select Committee on Small Business, United States Senate Part Two, 92nd Congress, 1st Sess., 1971, 462, 497, cites figures closer to 225 million.
By 1956, the year after the first minor tranquilizer, Miltown, was released, nearly one in twenty Americans had taken the drug. ${ }^{49}$ Such minor tranquilizers were replaced by benzodiazepine tranquilizers like Librium in the early 1960s. Librium was the country's bestselling drug until 1968 when Valium ascended to the top spot. Valium was the Western world's most prescribed medication from 1968 through $1981 .^{50}$

Most epidemiological studies suggest that approximately 20 percent of American adults used one of these drugs in most years during this time period, and well over half of American adults reported using a psychopharmacological drug at some point. ${ }^{59}$ Women comprised about 60 percent of users. General practitioners and family doctors, not psychiatric specialists, prescribed almost all of these drugs. By 1960, more than 75 percent of U.S. doctors had prescribed minor tranquilizers; in the early 1970s, 79 percent of Los Angeles physicians agreed that "certain medications are often very helpful in handling the social demands and stresses of everyday living." 52

49. Carl Elliott, Better Than Well: American Medicine Meets the American Dream (New York: Norton, 2003), 130.

50. "Hoffmann-La Roche Moves to Protect Librium Sales Rights," Wall Street Journal, January 21, 1975, 6; Gilbert Cant, "Valiumania," New York Times Magazine, February 1, 1976, 34-44; Ian Sample, "Leo Sternbach," The Guardian, October 2, 2005; Tone, Age of Anxiety, 153.

51. Hugh J. Parry, "Use of Psychotropic Drugs by U.S. Adults," Public Health Reports 83, no. 10 (1968): 799-802; Hugh J. Parry, Mitchell B. Balter, Glen D. Mellinger, Ira H. Cisin, and Dean I. Manheimer, "National Patterns of Psychotherapeutic Drug Use," Archives of General Psychiatry 28, no. 6 (1973): 769-83; Glen D. Mellinger, Mitchell B. Balter, and Dean I. Manheimer, "Patterns of Psychotropic Drug Use Among Adults in San Francisco," Archives of General Psychiatry 25, no. 5 (1971): 385-94; Smith, Social History, 37-61; Dean I. Manheimer, S.T. Davidson, Mitchell B. Balter, Glen D. Mellinger, Ira H. Cisin, and Hugh J. Parry, "Popular Attitudes and Beliefs about Tranquilizers," American Journal of Psychiatry 130, no. 11 (1973): 1246-53; Balter and Levine, "The Nature and Extent of Psychotropic Drug Usage"; Janice K. Clinthorne, Ira H. Cisin, Mitchell B. Balter, Glen D. Mellinger, and Eberhard H. Uhlenhuth, "Changes in Popular Attitudes and Beliefs about Tranquilizers, 1970-1979," Archives of General Psychiatry 43, no. 6 (1986): 527-32; "A Small Fix for America's Drug Habit," editorial, New York Times, July 17, 1980, A18.

52. "Tightening the Lid on Legal Drugs," 382; Stephen N. Rosenberg, Louise B. Berenson, Florence Kavaler, Elihu A. Gorelik, and Benjamin Levine, "Prescribing Patterns in the New York City Medicaid Program," Medical Care 12, no. 2 (1974): 138-51; D. C. G. Skegg, Richard Doll, and J. Perry, "Use of Medicines in General Practice," British Medical Journal 1, no. 6076 (1977): 1561 -63; Lawrence S. Linn and Milton S. Davis, "Use of Psychotherapeutic Drugs by Middle-Aged Women," Journal of Health and Social Behavior 12, no. 4 (1971): 331-430; Lawrence S. Linn, "Physician Characteristics and Attitudes toward Legitimate Use of Psychotherapeutic Drugs," Journal of Health and Social Behavior 12, no. 2 (1971): 132-40; Lawrence S. Linn and Milton S. Davis, "Physicians' Orientation toward the Legitimacy of Drug Use and Their Preferred Source of New Drug Information," Social Science E् Medicine 6, no. 2 (1972): 199-203; Ingrid Waldron, "Increased Prescribing of Valium, Librium, and Other Drugs-An Example of the Influence of Economic and Social Factors on the Practice of Medicine," International Journal of Health Services 7, no. 1 (1977): 41. 
These products repeatedly generated controversies and regulatory efforts regarding their overuse, misuse, side effects, and addictive potential. As one Stanford pharmacologist noted at a 1960 industry meeting prior to Valium's release, "if this drug is as good as these people say, it's going to be abused."53 Media organizations from Consumer Reports to local newspapers voiced concerns that animated regulatory action. ${ }^{54}$ National Institute of Mental Health (NIMH) Director Robert Felix wondered, in 1957, whether there were downsides to "the executive who [takes tranquilizers] to tide himself over a crisis that his predecessors sweat through," and in 1969 Felix's successor Stanley Yolles asked of a Senate committee, given widespread tranquilizer use, "to what extent would Western culture be altered by widespread use of tranquilizers? Would Yankee initiative disappear? Is the chemical deadening of anxiety harmful?"55 Social leaders from across the ideological spectrum, including Malcolm X, Betty Friedan, Herbert Marcuse, and Phyllis Chesler, spoke about these drugs' controversies and dangers. So too did cultural authorities like Roger Ebert in 1970's Beyond the Valley of the Dolls, and the Rolling Stones, whose 1966 hit "Mother's Little Helper" addressed issues of psychopharmaceutical misuse, overuse, addiction, and overdose. The year after "Mother's Little Helper" reached number 8 on the Billboard charts, aggregate yearly psychopharmaceutical prescriptions reached 180 million. ${ }^{56}$

During these changes, while most Americans expressed what leading American psychiatrist Gerald Klerman called "pharmacological Calvinism" and told survey researchers that people should use willpower instead of pills to deal with life's stresses, the public's revealed behavioral preferences in the form of consumption patterns indicated otherwise. ${ }^{57}$ As an advertising executive told the New Yorker in 1958, minor tranquilizers' successes were a result of "partly slugging away in there, partly just letting the thing roll on its own-you couldn't have stopped it."58

53. Tone, Age of Anxiety, 141.

54. "Unsettling Facts about Tranquilizers," Consumer Reports 23 (1958): 4; International News Service, "Doctor Warns of Addiction Danger to 'Peace' Pills," Lubbock Avalanche-Journal, September 29, 1956, 3; United Press International, "Happy Pills May Be Habit Forming, Study Reveals," Redlands Daily Facts, November 6, 1958, 9.

55. Herzberg, Happy Pills, 63; U.S. Congress, Senate, Select Committee on Small Business, Subcommittee on Monopoly, Competitive Problems in the Drug Industry: Hearings Before the Monopoly Subcommittee of the Select Committee on Small Business, 91st Congress, 1st Sess., 1969, 5276.

56. Tone, Age of Anxiety, 180, 178, 189; Ellen Herman, The Romance of American Psychology: Political Culture in an Age of Experts, 1940-1970 (Berkeley: University of California Press, 1995), 276303; U.S. Congress, Advertising of Proprietary Medicines, 497; Gerald L. Klerman, "Psychotropic Hedonism vs. Pharmacological Calvinism," The Hastings Center Report 2, no. 4 (1972): 3.

57. Klerman, "Psychotropic Hedonism"; Clinthorne et al., "Changes in Popular Attitudes."

58. Thomas Whiteside, "Onward and Upward with the Arts: Getting There First with Tranquility," New Yorker, May 3, 1958, 120.
Yet amid this "consumers' republic," when serious concerns repeatedly arose about overuse, misuse, side effects, abuse, and addiction, it fell to policymakers to attempt to restrict products' use or disincentivize their prescription. ${ }^{59}$ During the ensuing battles, President Richard Nixon fumed that "we have created in America a culture of drugs. We have produced an environment in which people come naturally to expect that they can take a pill for every problem-that they can find satisfaction and health and happiness in a handful of tablets or a few grains of powder." 60 Ultimately, over this period, policymakers and regulators across institutions of government would repeatedly try a range of approaches to regulating these products, but their efforts would prove to be halting and ineffective in large measure due to the pocket of weakness in the pharmaceutical regulatory structure.

\subsection{The "Muddle" of Mid-Twentieth-Century Post-Marketing Regulation}

These products entered into a mid-twentieth-century regulatory environment that occupied an uncomfortable space in between common consumer safety protection practices and law enforcement-based approaches associated with illegal drugs. In spite of the FDA's notable growth, reputation, and regulatory capacities, the agency's strengths were concentrated at the approval stage, and it was less interested in and less adapted to addressing problematic products already admitted into the medical marketplace.

The FDA had two primary roles in this early era: It was in charge of ensuring pre-market product safety and that products on the market were not "misbranded," with the latter duty discharged primarily with a focus on product labeling. This dual emphasis on pre-market safety and avoiding misbranded products defined the terrain atop which subsequent regulatory battles and reforms would be fought and layered. ${ }^{61}$ These duties and their associated powers emerged through both legislation and agency rule setting. For the first half of the twentieth century, for products with potentially habit-forming or dangerous effects, these decisions revolved around whether drugs would be available over the counter or only with a prescription and labels warning about drug dangers. ${ }^{62}$ The agency's goal

59. Lizabeth Cohen, A Consumers' Republic: The Politics of Mass Consumption in Postwar America (New York: Knopf, 2003).

60. Richard M. Nixon, "Remarks to the American Medical Association's House of Delegates Meeting in Atlantic City, New Jersey" (June 22, 1971), in The American Presidency Project, ed. Gerhard Peters and John T. Woolley, http://www.presidency.ucsb. $\mathrm{edu} / \mathrm{ws} /$ ?pid=3051.

61. I thank an anonymous reviewer for underscoring layering.

62. Swann, "FDA and the Practice of Pharmacy"; Swann, "The Evolution of the American Pharmaceutical Industry"; John P. Swann, "Drug Abuse Control under FDA, 1938-1968," Public Health Reports 112, no. 1 (1997): 83-86; Wallace F. Janssen, 
was to address proper safety and labeling requirements to ensure conscientiousness and oversight by pharmacists and doctors, and legal, safe, and wellinformed self-medication.

The 1938 Food, Drug, and Cosmetic Act did not formally create a category of prescription-only drugs. But because certain drugs were not safe for self-medication due to toxicity or harmful effects, the FDA developed, through formal regulation and informal encouragement, a system whereby firms could voluntarily make their products prescription only. If firms made a product prescription only, they no longer needed to provide detailed prescribing directions and informational drug labels, effectively shifting responsibility for safe and proper prescribing from the therapeutic firms to individual doctors, pharmacists, and consumers. The basic prescription label sent from manufacturers to physicians read "Caution: To be used only by or on the prescription of a physician." 63

To ensure that certain drugs were more likely to come under prescription requirements, the FDA also declared that some drugs, including barbiturates and amphetamines, were toxic or had harmful effects and therefore required the medical supervision of a physician and were not available for selfmedication, as they would then be misbranded. ${ }^{64}$ Firms responded by labeling nearly all of their products prescription only. Doing so freed firms of potential misbranding claims, but clouded the FDA's effort to communicate to doctors and pharmacists, and by extension to consumers, that some products were less safe than others.

Because the FDA's enforcement capabilities did not extend to ordinary medical practitioners, only to producers, the legal and informational confusion surrounding its chief means of post-marketing regulation required clarification, which regulators, legislators, and industry increasingly recognized. ${ }^{65}$ As the FDA's official historians have argued of the 1938

"Outline of the History of U.S. Drug Regulation and Labeling," Food, Drug, and Cosmetic Law Journal 36, no. 8 (1981): 420-41; Jonathon Erlen and Joseph F. Spillane, eds., Federal Drug Control: The Evolution of Policy and Practice (Binghamton, NY: Pharmaceutical Products Press, 2004); Wallace F. Janssen, "The Story of the Laws behind the Labels," FDA Consumer 15, no. 5 (1981): 32-45; Peter Barton Hutt, "Turning Points in FDA History," in Perspectives on Risk and Regulation: The FDA at 100, ed. Arthur Daemmrich and Joanna Radin (Philadelphia, PA: Chemical Heritage Foundation, 2007), 14-25. The agency did not yet control advertisements. History."

63. Janssen, "The Story of the Laws"; Janssen, "Outline of the

64. Swann, "FDA and the Practice of Pharmacy"; Swann, "Drug Abuse Control."

65. As the FDA noted, "200 Federal inspectors are obviously unable to regulate the practices of over 50,000 retail drug stores," quoted in Swann, "FDA and the Practice of Pharmacy," 63. legislation and the regulations that followed, while "the New Drug section, in contrast, was clear and comprehensive," the law "had fallen far short of providing a clear, complete, and workable system of drug regulation and labeling," leaving "a pharmaceutical muddle by $1951 . "{ }^{\circ}$

It was amid this "muddle" that the public and policymakers grew more concerned about popular psychopharmaceuticals like barbiturates and amphetamines. States attempted to fill this gap by passing limited barbiturate control laws. The FDA, to the extent that it could, used its enforcement agents, who numbered in the low hundreds, to eliminate large-scale illegal production and distribution of barbiturates and amphetamines. ${ }^{67}$ Though a significant expenditure of resources and a good faith effort, the policing and enforcement route was, policymakers would come to realize, only effective in addressing a small number of the most egregious illegal producers and distributors, and it was of limited utility as a broader policy tool for affecting prescription and consumption. ${ }^{68}$

Surgeon General Thomas Parran moved to address these issues in 1947. With Parran's support and in consultation with the FDA, Representative Edith Nourse Rogers introduced a bill bringing barbiturates under the federal statute regulating illegal drugs, the Harrison Narcotic Act. ${ }^{69}$ The mechanism proposed was law enforcement based and analogized legal pharmaceuticals to illegal drugs. In opposition, private physician, pharmacy, and pharmaceutical interest groups joined with the government's enforcement arm, Harry J. Anslinger's Federal Bureau of Narcotics (FBN), to defeat the bill. These private groups, such as the American Medical Association (AMA), wanted to retain professional autonomy, and the public enforcers wanted to avoid policing the medical practices of ordinary Americans seeking pharmaceutical relief through their neighborhood doctors and pharmacists in communities across the country. ${ }^{70}$

66. Janssen, "Outline of the History," 430; Swann, "FDA and the Practice of Pharmacy," 12; Temin, Taking Your Medicine, 51-53.

67. Associated Press, "Risky Drugs, Poison Foods Bother FDA," Washington Post, February 7, 1951, 6; Swann, "Drug Abuse Control"; Swann, "FDA and the Practice of Pharmacy."

68. Frydl, The Drug Wars in America, 180-200, extensively documents these dynamics, tensions, and limitations.

69. Richard L. Williams, "'To Sleep: Perchance...' With Pills," Life, October 13, 1952, 105-18; Nicolas Rasmussen, "Goofball Panic: Barbiturates, 'Dangerous' and Addictive Drugs, and the Regulation of Medicine in Postwar America," in Prescribed: Writing, Filling, Using, and Abusing the Prescription in Modern America, ed. Jeremy A. Greene and Elizabeth Siegel Watkins (Baltimore, MD: Johns Hopkins University Press, 2012), 23-45; Nicolas Rasmussen, “Controlling ‘America's Opium': Barbiturate Abuse, Pharmaceutical Regulation, and the Politics of Public Health in the Early Postwar United States," Journal of Policy History 29, no. 4 (2017): 543-68; Frydl, The Drug Wars in America, 165-66.

70. King, The Drug Hang-Up, chap. 25. 


\section{3. "To Shield Foolish Women": Creating Limited Prescription Requirements for "Dangerous Drugs" in the Early to Mid-1950s}

In 1951, a seemingly more comprehensive solution than the midcentury muddle arrived with the passage of the Durham-Humphrey Amendment, which required mandatory prescription status for "dangerous drugs." Sponsored by two former pharmacists, Senator Hubert Humphrey and Representative Carl Durham, the law dictated that a range of products could only be sold with a doctor's prescription: "dangerous drugs" requiring medical supervision, drugs with specific habit-forming ingredients, and drugs whose New Drug Application approval determined that they necessitated supervision. Labels on products sent from manufacturers to physicians and pharmacists were required to read, "Caution: Federal law prohibits dispensing without a prescription." ${ }^{71}$ Unlimited refills were permitted, no recordkeeping was required, and the law did not stipulate personal possession limits. The bottle given from the druggist to the consumer had to include the druggist's name and address, the prescribing doctor's name, the prescription number, date, directions for use, and any necessary cautionary statements. The law was assumed to include barbiturates, amphetamines, and tranquilizers. ${ }^{72}$ In codifying a detailed formal prescription requirement for the dispensing of dangerous drugs, the amendment formalized into statute what the FDA had attempted via administrative action.

Even these limited requirements did not pass without controversy, and the means by which the 30,000 drugs already on the market were to be deemed "dangerous" ignited an intense dispute. The FDA wanted to retain this power by formalizing via statute what it had done informally in the prior decades, and it preferred to allow the Federal Security Agency (FSA) administrator, at the FDA's behest, to add and remove products from among those deemed dangerous. Under the agency's favored approach, manufacturers would have to show an absence of danger to overturn a ruling. This proposal would have adopted a precautionary principle, with a burden placed on industry to prove safety, rather than a burden placed on government to prove harm.

71. Alan Lyles, "Promoting Pharmaceutical Products," in Handbook of Pharmaceutical Public Policy, ed. Thomas R. Fulda and Albert I. Wertheimer (New York: Pharmaceutical Products Press, 2007), 373.

72. Food, Drug, and Cosmetic Act Amendments of 1951, PL 82-215 (1951); Gregory W. Reilly, "The FDA and Plan B: The Legislative History of the Durham-Humphrey Amendments and the Consideration of Social Harms in the Rx-OTC Switch," in Food and Drug Law: An Electronic Book of Student Papers, ed. Peter Barton Hutt (2012), https://dash.harvard.edu/handle/1/8965550.
The pharmaceutical industry, the medical profession, Republicans, and conservative Democrats were opposed to this component of the proposed DurhamHumphrey law. Those opposed wanted to protect popular products from restriction and to avoid granting liberal FSA Administrator Oscar Ewing, who had strongly advocated for national health insurance, additional powers. The opposition proved successful. By passing an amendment offered by Congressman Joseph O'Hara with the Durham-Humphrey Amendment, those favoring looser regulation stripped the FDA of the administrative power, initially granted in 1938, to deem drugs dangerous and effectively prescription only, and instead required the agency to go through laborious and expensive test cases to remove "dangerous" products from over the counter status. Though the agency preferred the initial administrative route and wanted to avoid a litigious process that was lengthy and costly given its small and stretched legal staff, the FDA eventually agreed to the O'Hara Amendment in order to get the broader 1951 legislative package passed. ${ }^{73}$

When the Durham-Humphrey Amendment became law, FDA Commissioner George Larrick argued that the legislation would, among other things, protect ordinary consumers from the overuse and misuse of powerful and potentially addictive drugs. Referring to one then-contemporary controversy to illustrate its benefits, Larrick argued that the legislation would effectively "shield foolish women who use a potent drug [amphetamines] to reduce instead of pushing the table away." ${ }^{, 4}$

The new Durham-Humphrey procedures were, however, quickly recognized as insufficient for addressing the problem of misuse and overuse of dangerous and addictive legal drugs. Discussions about a separate enforcement-based drug law that passed Congress the following week, the 1951 Boggs Act, clearly identified these shortcomings. The act imposed mandatory minimum sentences and financial penalties for illegal drug possession and sale. Throughout discussions of the Boggs Act, policymakers recognized the FDA's inadequate ability to address the barbiturate and amphetamine problem, but no practicable policy solution appeared.

While regulators and policymakers agreed with Harris Isbell, head of the Public Health Service's Lexington, Kentucky, narcotic treatment facility, who argued that barbiturates were more addictive than any other legal or illegal drug, FBN chief Anslinger argued that the problem with these drugs was not illegal distribution as such, but that policing prescribing and consumption would be logistically impossible and politically unpopular. Anslinger successfully "put

73. Reilly, "The FDA and Plan B," 14-27.

74. "U.S. Revises Rules on Drug Labeling: Ewing Sets Order on Marking of Non-Prescription and Prescription Medicines," New York Times, February 6, 1952, 32. 
sandbags up against the door" whenever the prospect of the government extensively policing the prescribing and consumption of legal drugs arose. Accordingly, in 1951, popular psychopharmaceuticals formally came under the relatively limited prescription requirements of the Durham-Humphrey Amendment, and although they were a large part of the more extensive discussion about illegal drugs, they were excluded from the Boggs Act's stronger policies, which applied only to the illegal and higher profile set of substances that were more politically attractive and logistically straightforward for legislators to confront. ${ }^{75}$

A similar pattern of problem recognition and limited policy repeated throughout the early to mid-1950s. FDA Commissioner Larrick spoke in favor of greater attention to and control over legal drugs given their dangers, but major pieces of drug legislation did not address these issues. This held true, as with the 1951 Boggs Act, for the later 1956 Narcotic Control Act. Dangerous pharmaceuticals were considered at length in congressional hearings on the 1956 act. $^{76}$ Solutions were repeatedly recognized as necessary. But policy answers addressing the problems that could be supported by the relevant scientific, regulatory, enforcement, and private entities were not forthcoming. As the act passed, the House of Representatives' 1956 report on the bill recognized the large problems with pharmaceuticals, but concluded ambiguously, without offering clear policy recommendations, that they should not be regulated like illegal drugs and that states might enact controls. ${ }^{77}$

Larrick, in discussions with Congress about the bill, conceded that new laws were necessary because the FDA could not adequately regulate ordinary prescribing and misuse or abuse of these drugs, but he too did not offer specifics. An FDA deputy commissioner, John Harvey, likewise noted that consumers lack the information necessary to make informed decisions, but offered no policy suggestions. When Representative Frank Karsten asked the agency's representatives if they would "classify barbiturates as a much more serious problem, affecting many more people, perhaps, than the narcotics problem ... because of the ease with which it can be obtained?" Harvey

75. David F. Musto, The American Disease: Origins of Narcotic Control (New York: Oxford University Press, 1999), 213, 222; Harry J. Anslinger, "The Federal Narcotic Laws," Food, Drug, and Cosmetic Law Journal 6, no. 10 (1951): 743-48; Williams, “To Sleep: Perchance..."; "Legislators Gun for 'Goof Balls," Amarillo Daily News, May 23, 1951, 1, 8; U.S. Congress, House, Committee on Ways and Means, Subcommittee on Narcotics, Hearings on H.R. 3490 Before the Subcommittee on Narcotics of the House Committee on Ways and Means, 82nd Congress, 1st Sess., 1951.

76. These issues occupied more than half of the hearings, Herzberg, Happy Pills, 93.

77. U.S. Congress, House, Committee on Ways and Means, Narcotic Control Act of 1956: A Report to Accompany H.R. 11619, 84th Congress, 2nd Sess., 1956, H. Rep. 2388, 50-75, recommendations at $74-75$. responded, "Yes ... the ease with which it can be obtained and the abundance of it; and, perhaps, the continued lack of recognition of the serious misuse of it." But he offered little in the way of policy guidance, merely noting only that "there is still room for education in the matter."

Just before Miltown's ascendance, Representative Hale Boggs conveyed Congress's recurrent frustration with this mid-1950s state of affairs: "Here Congress finds itself again with everyone admitting that this is a very grave problem. What we are trying to do is to find out how to face the problem and do something about it." Such claims reflect both a sincere preference for regulation but also strategic position taking without deeply engaging in difficult problem solving. Likewise, while the 1956 narcotics legislation passed in time for Boggs and others to claim credit for it during their political campaigns, it did not address pharmaceuticals. Anslinger's contention that "the medical profession [should] take hold of that situation and bring it under control," and that legislators should "see if the doctors cannot keep this stuff in the bottles and control it in that way, rather than to suddenly make it a police problem" remained the policy status quo-in effect, maintaining medical autonomy and relatively unencumbered private decision making. ${ }^{79}$

The weaknesses and difficulties of post-marketing regulation, and a lack of political capacity, will, and knowledge about how to address a complicated policy question, precluded solutions to these growing problems through the mid-1950s. There was no apparent and clearly effective policy option between the perceived poles of policing medical practices and rigidly preserving physician autonomy. Despite laws like the 1951 Durham-Humphrey Amendment, and despite other drug control efforts from the early and mid-1950s like the 1951 Boggs Act and the 1956 Narcotic Control Act, the absence of a clear and politically feasible solution and growing concerns with legal psychopharmaceutical overuse, misuse, abuse, and addiction ensured that these policy problems would remain live as a new set of products entered the marketplace and reached even greater levels of popularity and controversy.

\subsection{Fighting for Further Post-Marketing Controls from the Late 1950s to the Mid-1960s}

By the late 1950s and early 1960s, amphetamines and barbiturates remained popular, but the first true mass-market blockbusters of the era were the new

78. U.S. Congress, House, Committee on Ways and Means, Subcommittee on Narcotics, Traffic in, and Control of, Narcotics, Barbiturates, and Amphetamines: Hearings Before the Subcommittee on Narcotics of the Committee on Ways and Means, 84th Congress, 1955-1956, 238.

79. Ibid., 234, 192. 
"minor tranquilizers" Miltown and Equanil, released in 1955, which quickly became the country's bestselling drugs. Given the difficulty of producing systematic, reliable, and valid post-marketing surveillance data, reports of problems with these drugs, while growing, primarily came through media accounts and descriptions drawing on case studies and clinical experiences. In this environment, policymakers again recognized that the existing regulatory mechanisms were insufficiently addressing advertising, labeling, prescribing, and usage.

With respect to advertising, in 1958 hearings on "False and Misleading Advertisements in the Drug Industry," Congress focused on the regulatory problems involved in firms providing accurate information about tranquilizers in advertisements to doctors. FDA Medical Director Albert Holland agreed with the legislators' assessments, explaining, along with others, that formally the FDA only controlled labeling, while the Federal Trade Commission (FTC) controlled advertising. Further, as the resulting congressional report pointed out, the FTC lacked the medical expertise and scientific capacity to control the situation, a preexisting FTC and FDA "liaison agreement ... has not been utilized in the tranquilizer field," and Congress would need to adjust statutes if the problem of accurate advertising was to be addressed. $^{80}$

Even without formal control over advertising, though, the FDA still attempted to adjust the information environment by shaping advertising and labeling. Almost immediately after the minor tranquilizers were released and concerns arose about adverse events and misuse, overuse, and habituation risks, the agency worked to persuade the pharmaceutical industry both to clearly reveal the drug's side effects in its ads, and to make less general claims about the range of conditions that its bestselling products could treat in its marketing materials for doctors.

A series of FDA-industry exchanges about Miltown from the late 1950s provides an illustrative and intensive example of such a process. The full "Chronology of Principal Actions ... with Particular Reference to Habituation" for Miltown involved over a dozen communications back and forth between the regulator and the firm, an in-person meeting between the parties, and took more than a year from January 1957 through March 1958. This episode conveys both a persistent post-marketing regulatory effort and the weak results it would likely have on medical

80. U.S. Congress, House, Committee on Government Operations, Subcommittee on Legal and Monetary Affairs, False and Misleading Advertising (Prescription Tranquilizing Drugs): Hearings Before the Subcommittee on Legal and Monetary Affairs of the Committee on Government Operations, 85th Congress, 2nd Sess., 1958, 145-58 and U.S. Congress, House, Committee on Government Operations, False and Misleading Advertising (Prescription Tranquilizing Drugs): A Report, 85th Congress, 2nd Sess., 1958, H. Rep. 2668, 18. practice. At the conclusion of this lengthy dialogue, agency pressure led the company to agree to change its advertisements to doctors: These ads would stop calling Miltown "not addictive" and would note that "careful supervision" was required for "susceptible persons, for example, alcoholics," who had a "known propensity for taking excessive quantities of drugs." 81

This small change was unlikely to substantially affect medical practices. Yet such changes are nonetheless examples of persistent and legally ambitious post-marketing regulatory efforts by the FDA. Given the structure of the regulatory process and the agency's limited powers, changing advertisements from describing a product as nonaddictive was, in fact, a major victory.

Scientific agencies including the National Institutes of Health (NIH) were also aware of potential problems with these drugs. But like the regulators, the scientists were also unable to make strong statements about misuse, overuse, habituation, and dependence, in their case because of data limitations and the utility of these products for many patients, and in part because their budgets were somewhat dependent on further researching psychopharmaceuticals. At conferences in the late $1950 \mathrm{~s}$, the NIH and NIMH noted the apparent problems with tranquilizers, but, as NIMH head Robert Felix argued in 1957, "We do not know whether it is addictive or not. We do not know because we have not had time to study it." 82 Elsewhere Felix added that it might take ten years to develop sufficient data to determine whether, how, and under what conditions tranquilizers were addictive. A few years later, Felix admitted that "it's tragic but true that more and more people are walking through life with a chemically produced filmy veil. I feel sorry for them." 83 Again, policymakers were aware of public health problems, but the policy solutions they could envision or pursue were limited. Further, as the NIMH's internal 1957 Annual Report notes, the agency also wanted to avoid strict regulation of these products given its interests in researching pharmaceutical treatments for mental health issues. $^{84}$

81. U.S. Congress, Senate, Committee on Government Operations, Subcommittee on Reorganization and International Organization, Interagency Coordination in Drug Research and Regulation: Hearings Before the Subcommittee on Reorganization and International Organization of the Committee on Government Operations Part Four, 88th Congress, 1st Sess., 1963, 1401-403.

82. “American Psychiatric Association's Kline Hits Unfavorable Tranquilizer Publicity at Senate Hearing; National Institutes of Health Doctor Urges Nonrefillable Prescriptions," F-D-C Reports"The Pink Sheet,"June 10, 1957, 10-11 reprinted in U.S. Congress, Interagency Coordination, 1443.

83. Robert P. Goldman, "Instant Happiness," Ladies Home Journal 80, no. 8 (1963): 67-71, reprinted in U.S. Congress, Interagency Coordination, 1459.

84. National Institutes of Health, "Publications and Reports Section: National Institute of Mental Health, Annual Report, 
Consistent with the shortcomings apparent to the public and policymakers, Congress tried to address growing concerns with psychopharmaceuticals when reforming both general pharmaceutical regulation and other drug laws in the early to mid-1960s. These efforts principally took the forms of the Kefauver-Harris Amendments of 1962 and the Drug Abuse Control Amendments of 1965.

The 1962 Kefauver-Harris Amendments to the FDA's authorizing legislation focused primarily on pre-market testing and safety following the worldwide thalidomide disaster, but the hearings laying the groundwork for the law repeatedly addressed growing concerns about the new blockbuster psychopharmaceuticals. The law's champion, Senator Estes Kefauver, interrogated Carter Products' Frank Berger, who had invented Miltown, about the drug and addiction, and Berger was eventually forced to concede that, at the very least, when the drug was given at high doses and administered for a long period of time, some addictiveness in patients with addictive personalities might be likely. Kefauver was unsatisfied with Berger's limited claim: "If it is addictive for some patients, why shouldn't you put that warning in your advertisement?" Kefauver pushed further: "Most patients and a lot of other people certainly get around to taking these things at one time or another. Most of us have something wrong with ourselves some time," but "a general practitioner cannot possibly read all these articles in every field of medicine," and "if you are advertising the merits of a drug, you certainly ought to put in some mention of serious side effects." 85

Though such concerns were clearly among those motivating the landmark 1962 law, post-marketing issues and regulations were ultimately not centrally addressed by it. The final Kefauver-Harris legislation contained fourteen main provisions, but only three dealt with the post-marketing stage. In the few provisions addressing non-gatekeeping issues, the secretary of Health, Education, and Welfare (HEW) was given the power to suspend a drug's approval on an emergency temporary basis, with a hearing occurring later, if the secretary thought that the drug was an immediate severe danger, or to order it withdrawn from market for safety reasons. Firms were also required to immediately report to the FDA any new information they received about the safety and efficacy of drugs on the market, and regulations following the amendments required firms to keep files

Calendar Year 1957" in Annual Report of Program Activities, National Institutes of Health 1957, National Institute of Mental Health (Bethesda, MD: National Institutes of Health, 1957), 1-3. https://archive.org/ details/reportofprograma1957nati/page/n0.

85. U.S. Congress, Senate, Administered Prices in the Drug Industry: Hearings before the Subcommittee on Antitrust and Monopoly of the Committee on the Judiciary Part Sixteen, 86th Congress, 2nd Sess., 1960, 9124-25. about adverse reactions related to certain unexpected and severe responses to drugs. And advertisements for drugs, the control over which was transferred to the FDA, were required to be accurate and include information on side effects, contraindications, and effectiveness. ${ }^{86}$ The first of these provisions regarding product removal addressed cases like thalidomide and drug disasters leading to death or widespread serious harm, and not the regulation of products like the new and popular psychopharmaceuticals with less dramatic post-marketing risks. The second and third provisions did address the latter issues, but only by providing for the reporting of relatively limited additional information. The bill did not explicitly or substantially regulate or adjust the incentives for post-approval drug prescribing and access.

Instead, like most of its predecessors, the KefauverHarris Amendments largely focused on the gatekeeping veto: the amendments established formal pre-market testing phases and the provisions ultimately led to the FDA adopting both a standardized pre-market submission document and a system of evaluation that established the placebo-based, randomized, controlled trial as the foundation for demonstrating efficacy. ${ }^{87}$ Overall and unequivocally, "the primary policy lesson FDA officials drew from the thalidomide case was to emphasize pre-market testing." 88

Within this environment, as the psychopharmaceutical market continued to grow, so too did the problems and controversies associated with it, and policymakers moved to more directly attempt to slow its rise. By 1962, the year in which KefauverHarris passed, 90 million prescriptions were being written yearly for tranquilizers, barbiturates, and amphetamines. Compared to other categories of drugs, this was second only to antibiotics like penicillin, and psychopharmaceuticals were consumed by roughly one out of six American adults. ${ }^{89}$

Frustrated with patchwork and ineffective solutions for apparent problems of overuse, misuse, abuse, and addiction, and concerned with the apparent rise of illegal drug use, policymakers also worked to overhaul drug control laws in the early to mid-1960s. These efforts focused on high-profile illicit drugs with few legitimate defenders and about which policymakers cared the most, including marijuana, heroin, and LSD, but also addressed problems with licit medical

86. Joseph M. Pisani, "Drug Safety and the FDA," Food, Drug, Cosmetic Law Journal 21, no. 2 (1966): 68-77; Gary L. Boland, "Federal Regulation of Prescription Drug Advertising and Labeling," Boston College Law Review 12, no. 2 (1970): 203-66; "Congress Tightens Drug Regulations," in CQ Almanac 1962, 18th ed., no. 05-197-05-210 (Washington, DC: Congressional Quarterly, 1963).

87. Drug Amendments of 1962, PL 87-781 (1962); Daemmrich and Greene, "From Visible Harm to Relative Risk," 312.

88. Daemmrich, Pharmacopolitics, 29.

89. Goldman, "Instant Happiness," 67. These numbers would grow to 178 million in 1967, and 202 million in 1970, "Tightening the Lid on Legal Drugs,” 382. 
products like psychopharmaceuticals, thus directly bringing together illegal and legal drugs. Shared policy problems and the presumption of shared policy solutions conceptually joined the two categories, but while legislation clearly and forcefully addressed illegal drugs, affiliated ambitious efforts to regulate medical products were, yet again, halting and yielded less than forceful results.

In President John F. Kennedy's March 15, 1962, consumer message to Congress, as negotiations over Kefauver-Harris were underway, Kennedy argued that additional controls were necessary for barbiturates, amphetamines, and other dangerous drugs. Kennedy called for a White House conference on drug regulation, which was held that fall. ${ }^{90}$ The conference's initial Ad Hoc Committee Report specifically recognized pharmaceuticals and their insufficient control, though it offered no solutions, delegating that task to a medical profession that, it argued, "should adopt guidelines concerning their proper use." $" 1$

That the proceedings identified that such products would become more widely abused, since they were inexpensive, easy to use, and easy to acquire, was itself a notable step in bringing all of these substances and their common problems together, in spite of the absence of policy prescriptions at this stage. ${ }^{92}$ President Kennedy's official statement from the report noted that "society's gains will be illusory if we reduce the incidence of one kind of drug dependence, only to have new kinds of drugs substituted"; HEW Secretary Anthony Celebrezze added that "we badly need stricter controls over the manufacture and distribution of the addicting nonnarcotic drugs, which today constitute a major problem in enforcement"; and FDA Commissioner Larrick noted that the FDA became involved in these issues "by the back door" and faced a tension in dealing with addiction without being overly restrictive in its actions. ${ }^{93}$

Following the initial conference, the newly formed President's Advisory Commission on Narcotic and Drug Abuse, led by E. Barrett Prettyman and Dean Markham in 1963, acknowledged internally that it lacked the data necessary to most persuasively argue for substantially disincentivizing the prescription of or restricting access to the controversial psychopharmaceuticals. Further, though the commission

90. John F. Kennedy, "Special Message to the Congress on Protecting the Consumer Interest" (March 15, 1962), in The American Presidency Project, ed. Gerhard Peters and John T. Woolley, http:// www.presidency.ucsb.edu/ws/?pid=9108.

91. "Appendix One: Report of an Ad Hoc Panel on Drug Abuse," in Proceedings: White House Conference on Narcotic and Drug Abuse, September 27 and 28 (Washington, DC: Government Printing Office, 1962), 271-308, 301.

92. Proceedings: White House Conference on Narcotic and Drug Abuse (Washington, DC: Government Printing Office, 1962), xvi, xix, 63, 276, 279-90.

93. Ibid., 4, 10, 33. recommended new restrictions that extended across all types of blockbuster pharmaceuticals, including sedatives and hypnotics, stimulants, and tranquilizers, in these early stages, the commission did not want to posit a common solution to both narcotics and "psychotoxic" drugs, even though it recognized their shared problems. The commission, which acknowledged that legislation would be insufficient to comprehensively address the problems, did not want narcotic-style controls that "would seriously hamper legitimate medical use," nor did it want criminal penalties for ordinary users. ${ }^{94}$ In trying to determine how to strike a balance, it sought counsel from the AMA about what, in fact, constituted "legitimate medical use of these drugs" and on "the extent to which the use of dangerous drugs in medical practice should be limited." In response, the AMA refused to give guidance, did not directly answer the policymakers' query, voiced opposition to regulation, and avoided providing a regulatory benchmark of any kind, unless the commission could "extend the deadline considerably" for its request. ${ }^{95}$

As the bill advanced in 1964, debates over its provisions demonstrated the usual set of difficulties. One of the major forces pushing for greater regulation of psychopharmaceuticals, Senator Thomas Dodd, argued that the FDA's informational and educational approach, however strongly pursued, "just won't get anywhere with the problem." Dodd lamented that there were "no adequate federal controls," and thus only incentive-based solutions would work. Discussions as the bill progressed addressed the insufficiency of state laws, the problem of drug substitutability, the lack of useful data, and worries about infringing on proper medical use. Questions also arose about the mechanisms by which drugs would be placed under the proposed law's new controls, the degree to which the proposed restrictions would in fact burden medical practice and reshape its incentives, and the potential conflation of legal and illegal drugs. ${ }^{96}$

94. "Interim Report," President's Advisory Commission on Narcotic and Drug Abuse, 1388; "Final Report," President's Advisory Commission on Narcotic and Drug Abuse, 1398; "Interim Report-Summary," 1385, all of which are excerpted and reprinted in U.S. Congress, Senate, Committee on Government Operations, Subcommittee on Reorganization and International Organization, Interagency Coordination in Drug Research and Regulation: Hearings Before the Subcommittee on Reorganization and International Organization of the Committee on Government Operations Part Four, 88th Congress, 1st Sess., 1963.

95. F. J. L. Blasingame, "Letter to Honorable E. Barrett Prettyman, August 16, 1963," Interim and Final Reports: Background/ Related Material No. 1, March 1963-August 1963, in Papers of Dean F. Markham and the President's Advisory Commission on Narcotics, 1962-1963, 1963, ProQuest History Vault.

96. U.S. Congress, Senate, Committee on Labor and Public Welfare, Subcommittee on Health, Control of Psychotoxic Drugs: Hearing before the Subcommittee on Health of the Committee on Labor and Public Welfare, 88th Congress, 2nd Sess., 1964, 50, 47. 
Throughout this process, the primary political goal of Kennedy and Johnson administration officials was to address high-profile illegal drug problems, not the more complicated and less politically beneficial issue of popular and problematic psychopharmaceuticals. Though illegal and legal drugs were being simultaneously addressed, illegal drugs were prioritized for two central reasons. First, as Markham, the commission's co-chair, wrote about the illegal drug issue to the Johnson White House during deliberations on the bill, with "disproportionate attention in the press, television, and radio ... there is no comparable national problem where so much can be accomplished with such a small expenditure of money and interest." ${ }^{97}$ Given that illegal drugs lacked legitimate, organized, and well-resourced defenders, it would be relatively easy and inexpensive to attack them with tough regulations, allowing policymakers to secure a high-profile and low-cost political victory. As Markham handwrote at the bottom of a March 20, 1963, memo, "narcotics will be big in '64!!"98

Second, the administration wanted to avoid lengthy disputes over what were seen as secondary issues like pharmaceuticals when its limited political bandwidth was needed to address legislative priorities like Medicaid and Medicare. Securing high-profile wins on issues like Medicaid and Medicare would require significant political capital and policymaking attention, leaving little energy for issues with smaller political returns on investment like regulating legal drugs.

The final bill, the 1965 Drug Abuse Control Amendments, included barbiturates and amphetamines as subject to new regulations, but not widely used tranquilizers, because including them would have caused contestation and delay. Firms and organized medicine signaled their strong willingness to fight against inclusion of tranquilizers, opposition that could have delayed or prevented passing the more politically expedient and less contentious sections of the bill. Following discussions between Markham and Isbell about the bill's language on other drugs that might eventually be included under the act's provisions, the legislation instead allowed for the FDA to later bring additional drugs under the law's control that had "a potential for abuse because of its depressant or stimulant effect on the central nervous system." Congress received assurances from the FDA that it would soon move to include minor tranquilizers under the law via this

97. Dean F. Markham, "Memorandum for Lee White" (April 1, 1964), quoted in Musto and Korsmeyer, The Quest for Drug Control, 12.

98. Dean F. Markham, "Memorandum for Lee C. White" (March 20, 1963), Lee White General File, Narcotics, March 20November 13, 1963, in Civil Rights during the Kennedy Administration, 1961-1963, Part 3: The Civil Rights Files of Lee C. White, ProQuest History Vault. provision. Both the House and Senate Reports on the bill relayed these assurances and the expectation of quick review and inclusion, given that the administrative and scientific route to including them would likely prove easier than the legislative track. ${ }^{99}$

The 1965 amendments' requirements for legal drugs did not provide substantial incentives to deviate from problematic prescribing and consumption practices, though they did directly address the less politically contentious issues of illegal distribution and sale. Beyond new pharmaceutical counterfeiting provisions favorable to firms, the law's requirements were mostly related to recordkeeping, production, and distribution, but not prescribing. The amendments set up a chain of distribution; allowed for seizure even without interstate commerce; increased recordkeeping for manufacturers and distributors; required a formal and documented chain of custody and prescriber licensing; formalized registration, recordkeeping, and inspection requirements for all parties involved in production and dissemination; and made possession without a prescription or license a crime, with light penalties for illegal users, without mandatory minimum sentences. The amendments did prohibit the filling or refilling of prescriptions more than six months after issue and allowed no more than five refills. The legislation also created a new enforcement division and associated powers within the FDA, reintroducing a capacity that the FDA had pursued in the 1940s and 1950s but had moved away from as it grew to focus on its scientific mission. ${ }^{100}$ This new enforcement-focused Bureau of Drug Abuse Control initially received a great deal of favorable publicity, but it was minimally staffed, fit uncomfortably within a scientific agency, and was reorganized out of the FDA into the Department of Justice (DOJ) in 1968. ${ }^{101}$

In the mid-1960s, public concerns with popular and problematic psychopharmaceuticals were increasingly recognized in policy debates, new statutes, and new regulations. But the manner of recognition, scale of inclusion, and strength of regulation were limited. Accordingly, while Science optimistically predicted in 1965 that Congress would soon no longer need to address the problems of pharmaceutical drugs, old problems quickly reemerged. ${ }^{102}$

99. U.S. Congress, Senate, Committee on Labor and Public Welfare, Drug Abuse Control Amendments of 1965: A Report, 89th Congress, 1st Sess., 1965, S. Rep. 337; U.S. Congress, House, Committee on Interstate and Foreign Commerce, Drug Abuse Control Amendments of 1965: A Report, 89th Congress, 1st Sess., 1965, H. Rep. 130; Musto and Korsmeyer, The Quest for Drug Control, 34-35. (1965).

100. Drug Abuse Control Amendments of 1965, PL 89-74

101. Swann, "Drug Abuse Control under FDA," 84-86.

102. Elinor Langer, "Congress and Drugs: Political Interest in Drug Problem Is at Lowest Point in Five Years," Science 147, no. 3660 (1965): 846-48. 


\section{5. "Neither Science Nor Law Has Yet Learned to Control This Situation": Concern and Confusion in the Late 1960s}

From the streets of San Francisco's Haight-Ashbury District, where people followed Timothy Leary's exhortations to "turn on, tune in, drop out," to Midwestern suburbs and East Coast metropolises, the use of both legal and illegal drugs continued to grow in the mid- to late 1960s. In this era, it quickly became clear to policymakers that the minimal requirements of the 1965 Drug Abuse Control Amendments did not sufficiently address the concerns that animated the regulations and that these concerns were actually growing.

In 1968, President Lyndon Johnson's Crime Message to Congress argued that the 1965 law needed updating since "these powders and pills threaten our nation's health, vitality, and self-respect." The president added that "the present Federal laws dealing with these substances are a crazy quilt of inconsistent approaches and widely disparate criminal sanctions. Responsibility for their administration is found in no single Department of the Federal Government." "We can no longer deal with this major problem in a haphazard way," Johnson concluded. ${ }^{103}$

Regulators undertook a series of smaller legislative and administrative efforts, including new penalties, rehabilitation programs, reorganizations within HEW, and proposals for a government-produced prescription compendium for doctors, but an HEW pharmaceutical task force found these efforts ineffective, concluding that "industry profits have not been significantly reduced by new governmental regulations concerning drug safety, drug efficacy, or drug advertising." ${ }^{104}$ An internal FDA report from 1969 reached similar conclusions, noting that the agency was simply "not equipped to cope" with the many consumer safety problems arising with products already on the market, particularly given the agency's limited "legal authority and resources allocation." The FDA memo added that sectors of the economy with $\$ 130$ billion in sales and 60,000 companies, when compared to the agency's $\$ 72$ million budget and 4,500 employees, "outstripped our ability to assure the public that all is well." 105

From the agency's perspective, the most straightforward way to address these drug problems was to follow

103. Lyndon B. Johnson, "Special Message to the Congress on Crime and Law Enforcement: 'To Insure the Public Safety"' (February 7, 1968), in The American Presidency Project, ed. Gerhard Peters and John T. Woolley, http://www.presidency.ucsb.edu/ws/ ?pid=29237.

104. U.S. Department of Health, Education, and Welfare, "Task Force on Prescription Drugs: Progress Report" (August 30, 1968), reprinted in U.S. Congress, Competitive Problems in the Drug Industry, 90th Congress, 2nd Sess., 1968, 3797.

105. "Consumer Protection Lacking, FDA Report Finds," $C Q$ Weekly Report 27, pt. 2 (1969): 1552-53. through on the task Congress had delegated to it and that it had assured Congress it would complete, from the 1965 amendments: bringing popular tranquilizers under the 1965 law by finding that they had "a potential for abuse because of its depressant or stimulant effect on the central nervous system."

Following its advisory committees' suggestions, the FDA issued such a finding for Miltown and Equanil in early 1966 and for Librium and Valium in 1967. ${ }^{106}$ Internal deliberations over the changes demonstrate the many difficulties of restricting access to and disincentivizing these prescriptions given the limited tools available to regulators. The administration found it hard to produce sufficient scientific evidence of abuse, and so industry pushed back strongly to claims of abuse potential. While regulators wanted to bring the drugs under the law to constrain their growth, overuse, and abuse, the hearings focused on addiction, putting the FDA in a trying position given its data limitations and the difficulty of causally demonstrating abuse potential. Accordingly, even achieving these limited victories required the agency's finessing of procedures. ${ }^{107}$

Following the agency's initial 1966 ruling proposing to bring Miltown and Equanil under the 1965 statute's regulations, the Wall Street Journal's headline told readers, "Tranquilizers among 17 drugs FDA lists for strict control to enforce new law," with its article deeming this a "significant starting step." Notwithstanding the Journal's claims of "strict control," not only was the law under which these substances would be brought fairly weak, but the agency's administrative ruling was anything but final. Both industry and regulator knew that for highly profitable drugs still under patent protections, any such administrative ruling by the agency would be subject to potentially lengthy legal challenge by firms. Both also knew that the FDA preferred to avoid tying up its limited resources in legal proceedings that were not central to its mission of product approval, or that were not related to highly visible severe safety issues, like thalidomide, for which the agency would be directly blamed. $^{108}$

Industry's administrative challenge to the 1966 FDA ruling delayed the final ruling, which had to be issued from DOJ, until 1967 for Miltown and Equanil, and 1969 for Librium and Valium, with the agencies concluding, after more administrative hearings and evidentiary reviews, that "it is possible to develop tolerance to Librium and Valium, but that

106. The former had decreased in popularity and had been delisted from the U.S. Pharmacopoeia, "Letdown for Miltown," Time 85, no. 18 (1965): 95.

107. Shorter, Before Prozac, 73-125, extensively documents these hearings.

108. Jonathan Spivak, "Tranquilizers among 17 Drugs FDA Lists for Strict Control to Enforce New Law," Wall Street Journal, January 17, 1966, 8. 
it has not been frequently observed or reported." These delayed administrative rulings were also challenged, this time in court. While Carter lost in 1969 on Miltown and Equanil, Hoffmann-La Roche's case on Librium and Valium wound its way through the legal system until 1973, when it won on a technicality about documents not provided in the original hearing. These issues were ultimately resolved under the new 1970 Controlled Substances Act, but the intervening period's administrative politics meant that efforts to place these popular and profitable products under even the only form of relatively weak control available were halting and contested. ${ }^{109}$

As the 1970 Controlled Substances Act was being drafted, hearings held by Senator Gaylord Nelson identified the social and policy problems that remained on the agenda in the late 1960s and the policymaking difficulties involved in addressing them. Nelson, who had led an unprecedented charge to regulate oral contraceptives and provide women with drug information through a patient package insert, started his hearings with analogies to Aldous Huxley's dystopia Brave New World, in which soma was the popular pharmaceutical of choice. Nelson argued that "in the nearly 40 years since Huxley created his classic the fiction began to read like reality. It became a prophetic insight into the kind of society we seem to be moving toward today," and that "Americans have been insulating themselves from the pressures of modern life by using tranquilizing drugs in rapidly increasing numbers." 110 Yet the tensions involved in addressing these problems were clear: Nelson noted that, from the regulatory perspective, "we don't really know very much about the tranquilizing drugs," NIMH Director Stanley Yolles referenced a large research apparatus devoted to developing new drugs, and others, rather than blaming regulators or policymakers for the problems, blamed excessive drug advertisements and cavalier doctors. ${ }^{111}$

As the legislators worked on the 1970 statute, celebrated anthropologist Margaret Mead offered the era's most insightful testimony on the issues facing both policymakers and broader society. Mead argued that policymakers were faced with resolving

109. U.S. Congress, Senate, Committee on the Judiciary, Subcommittee to Investigate Juvenile Delinquency, Narcotics Legislation: Hearings before the Subcommittee to Investigate Juvenile Delinquency of the Committee on the Judiciary, 91st Congress, 1st Sess., 1969, 617-61, 952-55; Carter-Wallace, Inc. v. Gardner, 417 F.2d 1086, 1969; Hoffmann-La Roche, Inc. v. Kleindienst, 478 F.2d 1, 1973; John Pekkanen, "The Tranquilizer War: Controlling Librium and Valium," New Republic 173, no. 2 (1975): 17-19.

110. U.S. Congress, Competitive Problems in the Drug Industry, 91st Congress, 1st Sess., 1969, 5273. For Huxley's related predictions in the year after the first minor tranquilizer's release, see "'Behavior' Drugs Now Envisioned,” New York Times, October 19, 1956, 29.

111. U.S. Congress, Competitive Problems in the Drug Industry, 91st Congress, 1st Sess., 1969, 5273, 5326-99. two contradictory and fundamentally American impulses: "a very strong bias against any chemical of any sort which alters mood, makes life seem less difficult than it is, puts one to sleep when one is kept awake by worries," versus "a policy that invention, technology, ingenuity, resources ought to be available to deal with anything that we want to have dealt with" and "a general emphasis in this country upon finding external solutions to all problems." She noted the wide swathe of conditions between the very ill institutionalized psychotic and the overtranquilized "zombie mother" and explained that drawing bright lines, the very task facing policymakers, is exceedingly difficult medically, culturally, and politically. Mead concluded that given the many stressful and difficult features of modern American life, it might indeed be useful to take a stimulant in the morning and a tranquilizer at night. ${ }^{112}$

While recognizing such tensions and complexities, it remained clear to policymakers that the overuse, abuse, and addiction problems had continued to grow and needed to be addressed. Researchers from the NIH explained in 1969 that the 1965 amendments had actually increased new and refill prescriptions for minor tranquilizers, with consumers substituting away from older and more highly regulated products and toward these newer and less regulated products. Further, according to the NIH, about 25 percent of all adult Americans had used a minor tranquilizer in the last month, and 50 percent of all Americans had used these products over their lifetime. ${ }^{113}$ Yet the core of the problem, and the optimal solution, were less clear. Officials from the NIMH noted that while the available data "do not indicate that a large proportion of Americans are becoming chronic or dependent users of psychotropic drugs," nonetheless "occasional use of psychotropic drugs to improve adequate social functioning and offset or prevent mild discomfort may very well be on the rise." Asked whether the latter was illegal, one NIMH official explained, "I do not think we want to call that necessarily illicit use in terms of narcotic drug abuse and other abuses." Likewise, the government scientists avoided discussing side effects and misuse (regulators' primary concerns) and instead focused on an absence of "major harmful effects."

112. Ibid., 5456-77. In response to the latter suggestion, Senator Bob Dole responded that perhaps he should tranquilize his office staff when things turned hectic, having earlier joked about using amphetamines during campaign season; see ibid., 5302. On the tensions Mead outlines, see James A. Morone, Hellfire Nation: The Politics of Sin in American History (New Haven, CT: Yale University Press, 2003).

113. Of all such prescriptions, the vast majority were given by general practitioners and for their psychological effects. U.S. Congress, Competitive Problems in the Drug Industry, 91st Congress, 1st Sess., 1969, 5293-94, 5296-97.

114. Ibid., 5299, 5303, 5293, 5303. 
Policy uncertainty and disagreement over what and how to regulate dominated the Nelson hearings, with regulators focused on the extremes of addiction and their formal legal duties, and legislators seeking to address broader public policy problems of overuse, misuse, and abuse. This gap between regulators and legislators is notable: It was apparent that a public health problem existed, but there was no one who could or would sufficiently address it. Nelson wondered who actually controlled these drugs, who should be in charge, and who had final decisionmaking authority between the scientists at the FDA and the law enforcement officials at DOJ. Yolles responded that these were ultimately decisions that political officials would have to make: "It is one thing to reverse situations in an illness, but the ability to change what has been considered normal in order to improve the norm is something else again. The choices among evils, dangers, and eventual good resulting from such manipulations can and will be made; but the questions are by whom and for what purpose?" He concluded by analogizing the regulatory bind facing legislators dealing with scientific and cultural change to the foreign policy bind created by the nuclear dilemma: "no amount of breast beating and cries of 'mea culpa' will put the stopper back in the pill bottle, any more than it put the old-fashioned atom together again ... the people have already proved that drugs developed in the laboratory are self-prescribed by the general population. Neither science nor law has yet learned to control this situation." 115

Though Yolles encouraged legislators to take the lead and finally draw bright lines, and though a major rewriting of drug laws was underway, these impending attempts at solutions would again lack the clear policy decision that Yolles suggested the legislators should produce.

\subsection{Drug Schedules, The Controlled Substances Act of 1970, and the Politics of Drug Categorization}

The era's most significant piece of drug legislation was the 1970 Controlled Substances Act, which brought all drugs of abuse under a common regulatory scheme. The act created different categories ("schedules") of control for licit and illicit drugs and remains the bedrock of the contemporary regulation of drugs of abuse and their manufacture, distribution, possession, use, and importation. Like its statutory and administrative precursors, the circumstances of the 1970 act's development, the debates over its passage, and the features of its enactment and implementation demonstrate the difficulty of post-marketing drug regulation and the importance of this pocket of weakness in the American regulatory state.

115. Ibid., 5276, 5278.
The process leading to this major revision of U.S. drug laws began in 1968 at the close of the Johnson administration, when the National Commission on Reform of the Federal Criminal Laws was tasked with addressing the nation's growing drug problem. The commission delegated this task to the DOJ's drug enforcement arm, the Bureau of Narcotics and Dangerous Drugs, and in early 1969, it was undertaken by Michael Sonnenreich and John Dean from the new Nixon administration.

At the time, the Nixon administration faced a range of national problems, including a weak economy, conflicts over racial issues and civil rights, controversy about the war in Vietnam, and general civic unrest. In this environment, Nixon officials thought it was politically beneficial to be seen as aggressively addressing the "law and order" problem of drugs. The administration was principally concerned with passing tough new drug penalties for the most dangerous drugs that were to be placed on the strictest of the new law's schedules. ${ }^{116}$ To maximize political gains, officials wanted to pass the bill before the 1970 midterm elections, hoping that this would help Republicans weaken or overtake long-standing Democratic control of Congress.

Given these electoral incentives, the administration wanted to avoid including controversial measures that might generate opposition to the bill and delay its progress. For these reasons, officials in the Nixon administration focused on drugs like heroin, LSD, and marijuana, and not on the more popular pharmaceutical drugs that had well-organized, wellresourced, and vocal defenders who could potentially derail legislation. Within the administration, Attorney General John Mitchell worked on drafting an initial bill while also consulting with drug companies, pharmaceutical and medical interest groups, and congressional leaders. $^{117}$

As Mitchell and the DOJ crafted the bill, Mitchell's public advocacy, though often focused on illicit drugs, also addressed the nation's serious problems with pharmaceuticals. On April 17, 1970, Mitchell delivered a speech at the State Department to the Federal Wives Forum, a group of Republican spouses active in addressing drug abuse, regarding "Dependence on Drugs-Its Implications In Our Lives." In this speech, which was provided to and reported in national newspapers, Mitchell identified an emergent "pill-oriented society" in America. Further, Mitchell recognized the psychopharmaceutical problem as far larger than other drug issues: "There are in fact many more people using, and misusing, the psychotropic drugs - the sedatives, tranquilizers, and stimulants-than such drugs as marijuana or LSD or even the 'hard' addictive drugs like heroin and cocaine."

116. Musto and Korsmeyer, The Quest for Drug Control, 41, 58, 59. 117. Ibid., 38-71 
Mitchell went on to point out that in 1965, 58 million new prescriptions and 100 million refill prescriptions were written for psychotropic drugs, and that "one adult in four uses one or more types, and nearly half the adult population has used one or more of them at some time." 118

Although he clearly identified the importance of the pharmaceutical misuse and abuse problem, Mitchell was less clear when describing policy solutions for these issues. Instead of suggesting specific reforms, the attorney general merely noted that "there are no simple answers to this dilemma." He suggested that the government needed to focus more on "increased public awareness." Given that the administration's regulatory interests sat elsewhere and given that it preferred this tepid approach to pharmaceuticals in order to avoid controversy, those who wanted to more tightly regulate popular and problematic pharmaceutical drugs, in particular the longtime champion of stricter regulation, Senator Thomas Dodd, faced substantial headwinds. ${ }^{119}$

The initial bill did include the pharmaceuticals that Mitchell had lamented that so many Americans were misusing, but the administration's efforts to address legal drugs would be primarily driven by its twin desires of avoiding controversy and passing a bill addressing its real priorities, which were illicit, narcotic, and hard drugs. The bill covered all drugs, licit and illicit, and proposed four "schedules" of decreasing severity. The first schedule (I) was for drugs with no legitimate medical use, and the three schedules that followed (II, III, IV) addressed drugs with varying degrees of utility and danger, and attendant restrictions.

In the original Senate bill and hearings, amphetamines were placed on schedule II, the second most restrictive category, and most restrictive category for legal drugs. The FDA supported this move, as did powerful members of Congress like Representative Claude Pepper, who was a former patient of President Kennedy's infamous amphetamine prescriber, Dr. Max Jacobson, and favored tighter regulation. ${ }^{120}$ Products on schedule II were subject to stricter production quotas and recordkeeping requirements than products on the lower schedules.

The House placed amphetamines on the more lax schedule III. Representative Pepper's attempts to

118. John N. Mitchell, "Dependence on Drugs-Its Implications in Our Lives," United States Department of Justice (April 17, 1970), 3-4, http://www.justice.gov/ag/aghistory/mitchell/ 1970/04-17-1970.pdf. In 1970, 214 million prescriptions were issued for psychopharmaceuticals, 29 percent for hypnotics and sedatives, 13 percent for stimulants, 39 percent for tranquilizers, and 19 percent for antipsychotics and antidepressants, amounting to $\$ 972$ million in sales, National Commission on Marihuana and Drug Abuse, Drug Use in America: Problem in Perspective: Second Report (Washington, DC: Government Printing Office, 1973), 43.

119. Mitchell, "Dependence on Drugs," 4, 8.

120. Rasmussen, On Speed, 215. move these products onto a more restrictive schedule met resistance from his colleagues, who noted things like the "large pharmaceutical manufacturing interests centered in" their home district. ${ }^{121}$ In spite of the efforts of Pepper, Dodd, and Senator Thomas Eagleton, who noted the difficulties of administrative versus legislative drug scheduling, the ultimate conference bill placed amphetamines in schedule III, with only methamphetamines falling on schedule II. Soon after the bill passed, though, in 1971, amphetamines were moved to schedule II administratively, as were barbiturates the following year. $^{122}$

But it was the minor tranquilizers, the most profitable category of pharmaceuticals and the world's most widely used drugs, which generated the largest pharmaceutical controversy during debate over the Controlled Substances Act. On this subject, the Nixon White House was concerned about Senator Dodd, who was both powerful and deeply invested in these issues as a longtime champion of greater restrictions on pharmaceuticals. The White House feared that Dodd's firm commitment to forcefully regulating minor tranquilizers could jeopardize the broader bill.

Consistent with the administration's fear, Dodd placed the minor tranquilizers on schedule III. While Dodd demanded serious regulation of tranquilizers, the administration hoped to largely avoid the issue by making compromises with industry as the legislation progressed. Hoffmann-La Roche, the parent company of Valium, worked against Dodd's Senate bill, partnering with House leaders like Congressman Paul Rogers and former FDA head James Goddard. All of the actors opposed to Dodd's efforts either shared the Nixon administration's aim to quickly pass a bill that dealt harshly with illicit drugs and sparingly with popular and profitable legal drugs or were content acceding to the administration's desires to pass the bill given their higher-order policy preferences. For some legislators and regulators, passing the bill advanced their own interests, as they fought for what they believed were more important issues like community health funding and the maintenance of categorical health funding grants and avoided the controversy and policy complexity that would come with stronger regulation of the world's most popular drugs. ${ }^{123}$

121. Representative Robert McClory, speaking on H.R. 18583 (September 24, 1970), 91st Congress, 2nd Sess., Congressional Record 116, pt. 25, 33614.

122. James M. Graham, "Amphetamine Politics on Capitol Hill," Society 9, no. 3 (1972): 14-22.

123. Pekkanen, "The Tranquilizer War"; "Comprehensive Drug Control Bill Cleared by Congress," in CQ Almanac 1970, 26th ed., no. 03-531-03-539 (Washington, DC: Congressional Quarterly, 1971), http://library.cqpress.com/cqalmanac/cqal70-1293935; Graham, "Amphetamine Politics on Capitol Hill.” 
Senator Dodd, seeking stronger restrictions, went so far as to prevent Goddard and other government scientists opposed to strict regulation from testifying in his Senate hearings on the bill. Though barred from Dodd's Senate hearings, the House heard testimony from leading psychopharmacologists who argued against overlegislation, and who noted that responsible physicians were the most likely path to successfully addressing these issues and that "such physicians are not created by legislative fiat." Roche argued that if its products were to be included in the bill at all, they should be under a weaker schedule and certainly not on schedule III. ${ }^{124}$

Consistent with these arguments against regulation, the House bill did not list minor tranquilizers at all, excluding them from all of the proposed schedules. Dodd, who complained that both chambers of Congress were "overrun by Hoffmann-La Roche lobbyists," secured the placement of minor tranquilizers on schedule IV, the lowest schedule, in the Senate's final bill. But as some conservative senators foreshadowed, once the bill emerged from conference, the minor tranquilizers were ultimately left out of the final legislation and were not placed on any of the new schedules. ${ }^{125}$ The landmark statute integrated and revised existing drug laws by ultimately creating five schedules. It focused on enforcement and new penalties, which were strongest for schedules I and II, and set a unified control system for all products and production quotas for some. But at its passing, it did not include tranquilizers like Librium and Valium, products that were the most widely used and of greatest concern among pharmaceuticals. ${ }^{126}$

The new law also addressed the issues of future drug scheduling or rescheduling efforts and pharmaceutical data collection. A final point of contention during the legislative debate was whether the DOJ or HEW would control future drug scheduling. The scientific organs of government wanted to retain control over scientific decisions and also wanted to avoid listing alongside seemingly less legitimate substances drugs they were researching or found useful.

124. Mathea Falco, "The Pharmaceutical Industry and Drug Use and Misuse," in The Community's Response to Drug Use, ed. Stanley Einstein (Washington, DC: Pergamon, 1980), 317-38; Pekkanen, "The Tranquilizer War"; Graham, "Amphetamine Politics on Capitol Hill"; U.S. Congress, Drug Abuse Control Amendments: Hearings, 91st Congress, 2nd Sess., 1970, 541, 767-94; U.S. Congress, House, Committee on Ways and Means, Materials Prepared by the Administration Related to Proposed Legislation to Regulate Controlled Dangerous Substances and Amend Narcotics and Drug Laws, 91st Congress, 2nd Sess., 1970.

125. Graham, "Amphetamine Politics on Capitol Hill," 21, 1422; Pekkanen, "The Tranquilizer War," 19.

126. Comprehensive Drug Abuse Prevention and Control Act of 1970, PL 91-513 (1970); Joseph F. Spillane, "Debating the Controlled Substances Act," Drug and Alcohol Dependence 76, no. 1 (2004): 17-29; David T. Courtwright, "The Controlled Substances Act: How a 'Big Tent' Reform Became a Punitive Drug Law," Drug and Alcohol Dependence 76, no. 1 (2004): 9-15.
Similarly, given that the DOJ would be enforcing any decisions, it wanted to be the body making any final policy determinations. The resolution to this dispute that was amenable to the affected agencies was also amenable to industry: To schedule or reschedule drugs, written advice and consent given from the FDA and HEW to the attorney general and DOJ was required, and the final determination would rest with the DOJ. This process gave all agencies input and, for industry, opened the door to additional lengthy administrative hearings and procedures that could be further held up in court as delay tactics. ${ }^{127}$ The legislation also addressed data shortages and encouraged producing the types of data about pharmaceutical use that had previously been lacking.

But overall, the 1970 act did not strongly address most drug users and drug problems. Following sixteen months of work on the legislation, on the morning of October 27, 1970, President Nixon ate breakfast, met with Henry Kissinger in the Oval Office, and then left the White House for the DOJ, where he signed the 1970 drug law at a press conference, just a week before the midterm elections. ${ }^{128}$

\section{7. "A Dark Moment": The Politics of Drug Recategorization Under the 1970 Act}

The 1970 act stipulated that HEW and DOJ could work together to schedule and reschedule drugs, if they determined that a substance merited greater or lesser restrictions. ${ }^{129}$ This administrative process allowed such decisions to be partially insulated from the pressures that legislators faced as they put products into different categories in the initial statute. Though amphetamines and barbiturates were, at last, brought under stricter controls, intensive fights over the most popular and profitable products, minor tranquilizers, freed them from regulation for a time and only yielded weak regulation once they were finally scheduled and brought under the 1970 statute years later.

In 1971, after administrative hearings in 1970, amphetamines were added to schedule II, something both houses of Congress had tried a year earlier but ultimately did not do. Given the tighter restrictions, production quotas, and real disincentives provided by schedule II, amphetamine prescriptions dropped substantially in 1971 and 1972, by 40 percent each year. ${ }^{130}$ This scheduling activity effectively depopularized amphetamines for two decades, until the 1990s brought the large-scale prescription of stimulants for child and adult attention-deficit/hyperactivity

127. Musto and Korsmeyer, The Quest for Drug Control, 57, 58, 68. 128. The White House, "President Nixon's Daily Diary" (October 27, 1970), https://www.nixonlibrary.gov/virtuallibrary/ documents/PDD/1970/038\%20October\%2016-31\%201970.pdf.

129. Spillane, "Debating the Controlled Substances Act," 22. 130. Rasmussen, On Speed, 218-20. 
disorder (ADHD). ${ }^{131}$ Like amphetamines, in the early 1970s some barbiturates were put under schedule II, others remained on schedule III, and their prescription dropped off, though less steeply, and principally due to replacement by tranquilizers and other sedatives. ${ }^{132}$

With respect to minor tranquilizers, which were excluded from the 1970 law, Roche's earlier challenge to their inclusion under the 1965 law was still pending. Roche won its court challenge in 1973 on a technicality, but it was clear that it would lose its next appeal. Accordingly, in 1973, the DEA proposed and Roche agreed to place minor tranquilizers under the 1970 act, this time on schedule IV. ${ }^{133}$ On this second-lowest schedule, these drugs were subject to recordkeeping requirements and could be refilled no more than five times before a new prescription was required.

Some sales declines started around this time, with minor tranquilizer prescriptions dropping from 1973 to 1980 about 25 percent from a height of 100 million, of which about two-thirds were Valium. Yet it took two more years after this 1973 agreement, until 1975 , for the drugs to get scheduled. Journalists covering these issues cited the claims of executive branch officials, who attributed delays to the file getting lost amid government reorganizations, conservative administrations, and "bureaucracy." ${ }^{34}$ Congress also asked about the 1973 agreement to schedule the minor tranquilizers and why it was taking so long to come into force, and the FDA responded that it had "somewhat lost track of the entire proceeding" between court cases, authority transfers, administrative backlogs, and disorganization. ${ }^{135}$

The confusing, delayed, and meager efforts to finally schedule the minor tranquilizers are clarified by the later recollections of Joseph A. Califano Jr., who would eventually become HEW Secretary under President Jimmy Carter. At the time of these regulatory efforts, Califano was working as a lobbyist for Roche on behalf of his Washington, DC, law firm, Arnold \& Porter. As Califano recalls of these regulatory disputes in an autobiography written more than three decades after their resolution, he readily exploited the full panoply of legislative, executive,

131. Mayes et al., Medicating Children.

132. U.S. Department of Health and Human Services, Drug Abuse and Drug Abuse Research: The Third Triennial Report to Congress from the Secretary, Department of Health and Human Services, ADM 91-1704 (Rockville, MD: U.S. Department of Health and Human Services, 1991), 189-203.

133. "Controls on Hoffmann-La Roche's Librium, Valium, Asked by U.S. Unit; Firm Acquiesces," Wall Street Journal, August $16,1973,8$.

134. Pekkanen, "The Tranquilizer War," 19.

135. U.S. Congress, House, Committee on Government Operations, Special Studies Subcommittee, Evaluating the Federal Effort to Control Drug Abuse Part Four, Hearings Before a Subcommittee of the Committee on Government Operations, 93rd Congress, 1st Sess., 1973, 965, 948-84. judicial, and administrative delay tactics and veto points to keep his client's products off schedule or at most on a weak schedule. Califano claims credit for both the extensive administrative delays involved in scheduling and for the last minute insertion into the 1970 act of a fifth schedule, one specifically created for Roche and in anticipation of its products' eventual inclusion. ${ }^{136}$

Among his efforts, Califano recalls attempting to persuade the new Speaker of the House, Carl Albert, of his client, Roche's, correctness. As Califano made his case, Albert interrupted, removing a container full of Valium from his pocket: "You talking about these? ... These pills aren't dangerous," Califano recalls Albert claiming, "They're great. I take 'em all the time. I couldn't get through the day around here without them." 137 Of these regulatory battles more generally, Califano recalls his lack of reservations at the time: "throughout my representation of Hoffmann-La Roche on Capitol Hill, I had few second thoughts about what we were doing."138

These second thoughts would only come much later. Toward the end of his career, after retiring from government service, Califano founded and chaired the National Center on Addiction and Substance Abuse, where he advocated for more stringent drug regulations and more widespread addiction treatment. Ruminating on the minor tranquilizer regulation episodes of the 1970s in a later book on substance abuse, Califano expressed deep regret over his earlier antiregulation efforts: "To this day I wonder how many patients developed problems as a result of my lobbying to keep these tranquilizers free of stricter controls. I remember it as a dark moment in my private practice of law." 139

According to the headline writers for the New York Times, the controls the tranquilizers were finally subject to with their scheduling in 1975 were, as in the Wall Street Journal's earlier assessment of the 1965 controls they supplanted, "strict." ${ }^{140}$ But as Ms. magazine noted at the time, the delayed and halting controls did not actually go very far given the increasingly clear and widespread concerns with these products. ${ }^{141}$

136. Joseph A. Califano, Jr., Inside: A Public and Private Life (New York: PublicAffairs, 2004), 200-204. Reporting from these episodes notes "that Hoffmann-La Roche reportedly paid a Washington law firm three times the annual budget of the Senate subcommittee staff to assure that their drugs would remain uncontrolled"; Graham, "Amphetamine Politics on Capitol Hill," 21.

137. Califano, Inside, 202.

138. Ibid., 204.

139. Joseph A. Califano, Jr., High Society: How Substance Abuse Ravages America and What to Do about It (New York: PublicAffairs, 2007), 23-24.

140. Associated Press, "Two Tranquilizers, Librium and Valium, Face Strict Control," New York Times, June 2, 1975, 27.

141. Deborah Larned, "Woman's Body/Woman's Mind: Do You Take Valium?” Ms. 4, no. 5 (1975): 26-35. 
The effects of scheduling did not receive substantial formal study given persistent issues with data availability. Broad trends show minor tranquilizer use dropping 25-33 percent from their height to 1980, though much of this drop is likely related to broader cultural backlash and high-profile public controversies stemming from the tranquilizer addiction cases of television producer Barbara Gordon and First Lady Betty Ford. This decrease is also somewhat illusory, as they remained number one among drug categories even in 1980, and the use of such products quickly recovered and returned nearly to old levels, though under different labels-Xanax rather than Valium-by 1985. The available data show, predictably given the incentives levied, small effects for scheduling efforts beyond schedule II. There were few effects for drugs placed on schedules III and IV, which is where the most popular products, after significant delay, ended up in the mid-1970s. ${ }^{142}$

\section{8. "That is Unlikely to Be a Terribly Effective Strategy for Altering Physician Behavior": Regulating Advertising and Labeling after Kefauver-Harris}

Policymakers' most direct regulatory efforts attempted to restrict access to and disincentivize the prescription and consumption of psychopharmaceuticals. Beyond these "command and control" approaches, throughout the 1960s and 1970s the FDA also strongly exercised its new authority over pharmaceutical advertising and labeling, powers which the 1962 Kefauver-Harris Amendments formally granted it. As in its multiyear campaign in the late 1950s to adjust a few lines of text on Miltown's label, though, significant constraints on the agency's abilities to adjust advertising and labeling persisted through these later eras. These constraints remained even during the FDA's often-ambitious maneuvers in the 1960s and 1970s.

Some types of advertising still sat outside of the FDA's formal control, including gray areas like firm sponsorship of medical conferences or firm production of specialized issues of medical journals. Advertisements to doctors about a 1978-1979 Cornell University program on stress, for example, sponsored by Hoffmann-La Roche, left top FDA official Richard Crout "not entirely comfortable," but nonetheless extended "into legitimate first amendment rights." NIMH Director Herbert Pardes ultimately withdrew from attending the program after a lengthy back-and-forth with its leaders, but otherwise regulators could do little about it. ${ }^{143}$ The FDA found itself

142. Spillane, "Debating the Controlled Substances Act," 26; U.S. Department of Health and Human Services, Drug Abuse and Drug Abuse Research, 190; Robert Reinhold, "Tranquilizer Prescriptions Drop Sharply; So Does Reported Incidence of Abuse," New York Times, September 9, 1980, C1. $219-42$ similarly constrained when it could not regulate a 1975 supplementary medical journal issue that was sponsored by Wyeth to advertise its benzodiazepine Serax. Crout explained to Congress that while "the process through which this supplement to a medical publication was produced is cause for concern," the agency could not legally act to restrict or adjust it. ${ }^{144}$

In spite of such limitations, the agency did achieve some hard-fought changes and small victories related to advertising and labeling in this period. As a 1970 Senate study found, in response to the FDA employing its formal and informal powers, firms had improved the overall specificity and accuracy of drug advertisements since the 1962 amendments. In 1971, FDA Commissioner Charles Edwards sent a letter to all psychopharmaceutical companies asking them to cease advertising tranquilizers for the problems of daily living and stress. Over time, many of the companies complied. The promoters of Serentil, for example, retracted one such advertisement and conceded that their drug was not for problems of everyday living, but was actually a strong antipsychotic. Roche, on the front page of JAMA in 1978, changed its ads to say that its products were not for ordinary stress. After 1973, there were no advertisements for problems of daily living, and after 1975, the overall volume of ads decreased. ${ }^{145}$ The FDA also extracted concessions by getting firms to send out large numbers of "Dear Doctor" letters in which producers informed practitioners of changes to advertising and labeling. Edwards and the FDA clearly recognized that there was a real but imprecise line "between the frustrations of daily living and true mental illness," and the FDA acted within the bounds of its new authority over advertising to successfully narrow some of the uncertainty around the hazy line demarcating illness from wellness. ${ }^{146}$

Yet the processes of achieving such successes were slow, the agency's resources were still limited, and the likely efficacy of even strong efforts was questionable. While Commissioner Edwards proposed that the agency distribute an official drug bulletin each month to rebut the industry claims it found problematic but could not directly regulate, the bulletin was released only quarterly and was seldom aggressive (though it would become particularly aggressive against Librium and Valium during the Carter administration in the late 1970s). As Senator Thomas McIntyre told Edwards in 1971, "it sounds like a very slow arduous process with the consumer being the victim of the whole mess." Asked by Congress whether the FDA could "undo the damage already done" about the fact that "the idea of prescribing these drugs for

144. U.S. Congress, Competitive Problems in the Drug Industry, 94th Congress, 2nd Sess., 1976, 13930.

145. U.S. Congress, Use and Misuse of Benzodiazepines, 89; Smith, Social History, 189, 122-27; Herzberg, Happy Pills, 247 n. 20, 145.

146. U.S. Congress, Advertising of Proprietary Medicines, 427. 
everyday frustrations has been implanted in the mind of the physician," Edwards could only point to the bulletin and to existing efforts to educate and inform the medical community. ${ }^{147}$

Even agency successes against firms' advertising excesses brought new complications without clear solutions. In 1977, Roche's advertising and promotional divisions noticed that doctors were growing concerned about advertising changes, and that firm representatives needed to "handle the overuse confrontation," as "abuse and misuse poses a continued confrontation" during promotional efforts with practitioners. The firm's 1977 Western Region Plan also recognized that the FDA had just approved Valium for prescription to children, and so the company's salespeople could therefore "use the new indication in children to build interest and to illustrate the safety of Valium." In directing its salespeople, when countering concerns about abuse, misuse, and overuse, to promote Valium's safety by referring to its approval for children, Roche was able to use the FDA's extensive pre-market procedures and their legitimacy to undercut the agency's post-marketing efforts. $^{148}$

Meanwhile, of the nearly 27,000 pharmaceutical advertisements reviewed by the FDA in 1977, only ninety-seven saw regulatory action. Moreover, the agency did not order a single remedial advertising campaign. Given this limited regulatory action, industry representatives argued that this reflected prior successful regulation and the absence of any remaining problems. ${ }^{149}$ From the regulatory perspective, however, this was not only a story, as industry claimed, of previously successful adjustments and an absence of present problems, but of financial, conceptual, political, and legal constraints on the range of plausible regulatory interventions.

The era's most prominent public debate about psychopharmaceutical use and promotion followed the widely discussed tranquilizer addictions of television producer Barbara Gordon and First Lady Betty Ford, both revealed in the late 1970s. These episodes also demonstrate how even amid unusually highprofile public controversy, the regulatory structure and attendant political incentives surrounding pharmaceuticals and their advertising and labeling limited possible policy responses. In prominent hearings convened by Senator Edward Kennedy in 1978, the senator began with familiar addiction stories and strongly condemned minor tranquilizer

147. Ibid., 433, 446-48. 178.

148. U.S. Congress, Use and Misuse of Benzodiazepines, 177, 174,

149. U.S. Congress, House, Select Committee on Narcotics Abuse and Control, Abuse of Dangerous Licit and Illicit Drugs-Psychotropics, Phencyclidine (PCP), and Talwin: Hearings before the Select Committee on Narcotics Abuse and Control, 95th Congress, 2nd Sess., 1978, 197. manufacturers. Roche's CEO responded that, given the laws in place, these accounts of addiction "unquestionably involved the most classic disobeyance of the package insert that I have ever heard in my life," in spite of the fact that, as others pointed out, such information went only to practitioners, not consumers. Meanwhile, Senator Kennedy's committee and FDA were, by necessity, working with Valium's producers on any new legislation it might pursue. $^{150}$

During these episodes, the FDA's representative, Richard Crout, identified both his agency's concerns about contemporary prescribing and consumption practices and its concomitant inability to forcefully constrain them. Crout noted a "legitimate concern, which I personally share, that we are an 'overmedicated society.'" But Crout also recognized that questions of "[overprescription] relative to medical need ... cannot be answered with scientific certainty" and could only be resolved through arguments based on "differing value judgments" and any behaviors that followed from them. He added, "the average person dealing with the ordinary stresses of life does, as a medical matter, not need these drugs nor any other drugs. I think it is a matter of concern to us to see the drifting of the prescribing of these drugs toward the ordinary situations of life, and it is of great concern to see their promotion going that way." Yet when Kennedy asked specifically whether the drugs should be taken for stress, Crout defaulted to responses following from the existing regulatory apparatus: to the statutory technicalities of drug approval, the vagaries of marketing and prescribing, and the formal legal structures within which these products were used, labeled, and advertised, noting the ease of the indication-based drug approval system and the fact that the drug label, per FDA approval, said that these drugs could be used for situational anxiety and thus could be prescribed for stress. Crout concluded that in spite of his agency's efforts to police advertising as best it could, "that is unlikely to be a terribly effective strategy for altering physician behavior."151

Informational shortcomings also persisted, further constraining efforts to adjust advertising and labeling. Kennedy found that it was difficult for legislators and regulators to directly address the central problems of overuse, misuse, and side effects when, even with some new requirements for epidemiological data collection, "we cannot quantify how many people are taking these drugs for too long a time. We cannot quantify the percent of appropriate versus inappropriate use. We cannot, and we will not be able to, until there is a system of post-marketing surveillance

150. U.S. Congress, Use and Misuse of Benzodiazepines, 1-45, 163, $110-62$.

151. Ibid., 88, 91. 
of drugs in this country."152 Related, as researchers who had surveyed patients about the information they received from their doctors found, "perhaps the most serious source of concern raised in our survey is the lack of information our respondents reported receiving from their physicians about the nature and likely effects of Valium." Thus when Kennedy queried Crout about whether or not doctors have "enough and the right information, given the nature of the problem that we have heard about here today," Crout again noted the gap between any agency actions and their likely effects on medical practice: "I would say, from the standpoint of drug labeling, the labeling is correct. The labeling is not false and dishonest, the standard that we have in the food and drug law. The question is how effective are we in getting the true gestalt, the true message across. I am suggesting that we want to do our part, and try to do our part, but it is going to take a lot more than simply drug-labeling changes by us."153

Given these shortcomings, legislators and regulators used the large public controversy over Valium following First Lady Ford's addiction revelations and the late-1970s hearings to help advance additional controls. The House's companion hearings to the Kennedy hearings, led by Representative Lester Wolff, noted that "the misuse of psychotropic drugs have reached what could legitimately be called epidemic proportions" and exclusively blamed industry, not regulators, doctors, or consumers. The policy solutions proposed in the House, though, were largely politically, legally, or logistically unworkable: The House proposed that Congress should persuade the FDA to establish a committee to oversee prescribing practices and create an advisory council to set upper dosage limits, encouraged state professionalism laws and statutory language having the DEA informed of and responsive to all prescribing, and encouraged the passing of legislation that would limit controlled drugs' distribution, all the while recognizing that "the FDA has been reluctant to intrude upon the doctor-patient relationship," "the AMA appears reluctant to police itself," and "the pharmaceutical industry appears to try to sell as much of their drug products as possible regardless of the 'real' need for such products." 154

The public clamor, debate, and media attention did themselves have important effects, to which the FDA also contributed with its highly negative articles

152. Ibid., $1-2$.

153. Ibid., 437, 91.

154. U.S. Congress, Senate, Select Committee on Narcotics Abuse and Control, Polydrug Abuse-The Response of the Medical Profession and the Pharmaceutical Industry: A Report of the Select Committee on Narcotics Abuse and Control, 95th Congress, 2nd Sess., SCNAC-95-2-16, 1979, 30-33. about Valium in its outside-facing magazine. ${ }^{155}$ By 1980 tranquilizer and sedative use had dropped off about one-quarter from their highs, a significant, though largely temporary, change. But even FDA officials did not attribute this decline to regulation as such, but to the broader culture and awareness of which policymakers' efforts were only a small part. ${ }^{156}$

\section{9. "The Stress of Everyday Life Usually Does Not Require Treatment": A Final Regulatory Push before the Reagan Revolution}

The three most prominent and innovative policy proposals during this final period-before the Reagan administration, the diminishment of regulatory energy, and the ascendancy of antidepressants and then opioids - came in part through the FDA's work with Kennedy's committee in the late 1970s. The first proposed a major pharmaceutical law overhaul focused explicitly on the problem of post-marketing regulation. The proposal was not specific to psychopharmaceuticals, though it was partially motivated by and clearly included and targeted them. The bill rewrote a broader 1978 Carter administration proposal, but unlike the Carter bill, which focused mostly on speeding up pre-market approval, the Kennedy bill, the Drug Regulation Reform Act, strengthened the post-marketing regulatory process. The proposal would have provided for greater standardization, statutory authority for existing practices, and new agency powers over post-marketing surveillance, patient package inserts, physicians, and distribution, with the proposed trade-off of weakening pre-market stringency. 157

The FDA and the Senate strongly supported the bill, which Kennedy was able to quietly champion and pass through his chamber. Yet almost all other parties, including all regulated entities like therapeutic producers and organized medicine, strongly opposed the bill, and in spite of Kennedy's success in the Senate, the bill failed to pass the House. After the legislation's failure, other comparably large-scale solutions were not forthcoming. As FDA Commissioner Donald Kennedy observed during this era, "one of

155. Annabel Hecht, "Tranquilizers: Use, Abuse, and Dependency," FDA Consumer 12, no. 8 (1978): 20-23; "Overcoping with Valium," FDA Consumer 13, no. 10 (1979-1980): 20-23.

156. Victor Cohn, "Women's Drug Dependency Called an Epidemic," Washington Post, April 12, 1978, A2; Reinhold, "Tranquilizer Prescriptions Drop Sharply."

157. "Drug Law Reform," in CQ Almanac 1978, 34th ed. (Washington, DC: Congressional Quarterly, 1979): 631-32; Robert B. Greenberg, "The Kennedy Version of the Drug Regulation Reform Act," American Journal of Health-System Pharmacy 36, no. 9 (1979): 1230-34; Thomas Ascik, "The Drug Regulation Reform Act," The Heritage Foundation Issue Bulletin 26 (June 21, 1978): 119; S. 1075, Drug Regulation Reform Act of 1979, 96th Congress; U.S. Congress, Senate, Committee on Labor and Human Resources, Drug Regulation Reform Act of 1979: Report, 96th Congress, 1st Sess., 1979, S. Rep. 96-321. 
the difficulties is that the regulatory handles on the problem aren't as clear as they might be." 158

There was, however, some movement toward a second approach, one focused on information provision. This proposal entailed directly giving patients more information in the form of patient package inserts, a conceptual move beyond most previous tactics, which had addressed communication not to consumers but only from manufacturers to doctors and pharmacists. The first patient package insert was developed in 1968 and added to oral contraceptives in 1970. Following extensive debate and contestation, patient package inserts were added to other hormonal products for women throughout the 1970s. Increasingly, the patient package insert appeared to regulators as a plausible solution to some post-marketing difficulties generally and to the misuse and abuse of psychopharmaceuticals in particular. ${ }^{159}$

Policymakers pursued this idea from 1978 to 1980 , focusing on a patient package insert that would supply information about certain therapeutics' effects, side effects, intended uses, and any warnings. Legislators and regulators, marshaling the capabilities of the Senate and the FDA through high-profile hearings and a series of sharply critical articles in the FDA Consumer, sought to induce Roche into further cooperation with their efforts, which the firm had previously rebuffed. ${ }^{160}$ Yet any prospective patient package insert could not be required unless formally authorized by new statutory language, which Congress was unlikely to provide, and any insert mandated by the FDA in the absence of congressional authorization would invite extensive litigation and further delay. As Commissioner Kennedy explained in meetings with the National Consumers League in 1978 when developing this policy, existing law did not explicitly allow the FDA to require patientdirected information, and its pursuit of such requirements in the absence of clear statutory authority would yield lengthy and resource-intensive legal battles. Given these constraints, the FDA's only feasible means of adopting practices likely to be more effective than the status quo was working directly with the regulated firm and, ultimately, securing that firm's voluntary compliance. ${ }^{161}$

During this dialogue over package inserts, the agency pursued a third, also informational, approach. This tack entailed revising benzodiazepine labels to add warnings about withdrawal and to remove the "stress" and "stressful circumstances" indications. The FDA pushed for companies to revise their drug labels for anxiolytics like Valium, ultimately asking

158. U.S. Congress, Use and Abuse of Benzodiazepines, 125. 159. Watkins, On The Pill, 120-28.

160. Hecht, "Tranquilizers"; "Overcoping with Valium."

161. U.S. Congress, Use and Misuse of Benzodiazepines, 127-28;

Hughes and Brewin, The Tranquilizing of America, 251. that they substitute new labeling that added language about "transient situational disturbances" instead of "stress" and "stressful situations." While most companies were willing to comply, Roche resisted, only eventually acceding. ${ }^{92}$

In mid-1980, the FDA approved unprecedented new labeling for the most popular drugs in the world. The new label declared: "[drug name] is indicated for the management of anxiety disorders or for the short-term relief of the symptoms of anxiety. Anxiety or tension associated with the stress of everyday life usually does not require treatment with an anxiolytic." This final label was spearheaded by President Carter's new FDA commissioner, former pharmacist Jere Goyan, who served only briefly. Goyan controversially declared himself "a therapeutic nihilist" whose "general philosophy is the fewer drugs people take, the better off they are." In a July 1980 media campaign, the FDA issued dramatic press releases announcing the new labeling, garnering front-page coverage in which Goyan derided the fact that, with respect to anxiolytics and benzodiazepines, "millions of Americans are taking them habitually just to deal with the anxiety of living." Goyan added that "these drugs were not intended merely to deal with normal anxiety. I'm especially concerned about people continually taking these drugs without knowing that they are becoming physically and psychologically dependent." 163

Yet importantly, these new warnings were not patient package inserts as with oral contraceptives, nor were the new warnings on the labeling provided to consumers. Rather, the admonition that "anxiety or tension associated with the stress of everyday life usually does not require treatment with an anxiolytic" was to be sent only to doctors and pharmacists. This reflected the law and politics of such actions: Changes such as these had to be agreed to by the regulated firms. Firm compliance was necessary because the drug was already approved, no new decisive scientific data were being applied to the change, patient package inserts were not mandatory, and regulators nonetheless wanted some modicum of policy change while avoiding an expensive and lengthy legal battle.

In light of this 1980 revision to tranquilizer labels sent to doctors and pharmacists, the lead story of the New York Times reporting on the change stated that among the menu of policy options discussed in the late 1970 s, "the action was one of the least stringent measures the Federal drug agency could have taken." The head of Ralph Nader's Health Research Group, Sidney Wolfe, argued that benzodiazepines should

162. U.S. Congress, Use and Misuse of Benzodiazepines, 91, 143-62.

163. R. Jeffrey Smith, "Jere Goyan Brings Innovative Record to FDA," Science 206, no. 4415 (1979): 200-01; Robert Reinhold, "U.S. Wins Agreement on Warning to Doctors on Use of Tranquilizers," New York Times, July 11, 1980, A1. 
have been moved from the 1970 Drug Abuse Control Amendments' lax schedule IV to the stricter schedule II, which would have required production quotas, stricter recordkeeping, and a new prescription for every purchase. Sandra Willet of the National Consumers League deemed the adopted labeling adjustment, which was perhaps the most substantial policy change in the area in nearly a decade, "the mildest possible step." 164 The New York Times Editorial Board labeled the measure a "small fix for America's drug habit." 165 Even achieving this "small fix," though, required significant public controversies; lengthy, large-scale, and coordinated pressure; and policymaking efforts across organs of government.

Many press reports at the time noted that Valium prescriptions had already fallen by about a third, to nearly 40 million a year, and total benzodiazepine prescriptions had fallen to 70 million from about 90 million yearly. Valium refills in particular dropped, and its use shifted to older and sicker patients. Even though these changes in usage occurred before and amid the new regulatory pressures, some accounts suggest that these regulatory efforts were themselves strong and represent a dramatic success. ${ }^{166}$

But policy and usage data subsequent to these decreases and regulatory actions caution against any interpretation suggesting regulatory stringency and efficacy. In 1981 data from immediately after the labeling change, benzodiazepine use was already on the rise once again, Valium remained the number one drug in the country, and benzodiazepine prescriptions climbed back to 81 million by 1985 . Further, the proposed patient package insert program never got off the ground. The Carter administration and FDA Commissioner Goyan finalized a rule in the administration's final months in office requiring patient package inserts for some classes of drugs, including benzodiazepines. But this regulation and the patient package insert program were eliminated early in the new Reagan administration, which also quickly replaced the "therapeutic nihilist" and aggressive regulator Goyan. ${ }^{167}$

164. Reinhold, "U.S. Wins Agreement," A9.

165. "A Small Fix for America's Drug Habit."

166. Frydl, The Drug Wars in America, 347-48; Shorter, Before Prozac, 5, 10, 73-125, 126, suggest this, while the following offer more moderate assessments: Herzberg, Happy Pills, 97, 101, 105, 113; Whitaker, Anatomy of an Epidemic, 126-47.

167. Valium's patent ran out in 1984 , and by 1987 , a similar product, Xanax, was the number four drug in the country. "High Anxiety," Consumer Reports 58, no. 1 (1993): 19-24; U.S. Department of Health and Human Services, Drug Abuse and Drug Abuse Research, 189-94; "This Week: Reagan Freezes Drug Information Scheme," New Scientist 90, no. 1250 (1981): 206; William R. Barclay, "Patient Package Insert Regulations Stayed," Journal of the American Medical Association 246, no. 3 (1981): 252; "Prescription Drug Products; Revocation of Patient Package Insert Requirements," Federal Register 47, no. 173 (September 7, 1982), 39147; Elizabeth Siegel Watkins, The Estrogen Elixir: A History of Hormone
Once again, following the extensive efforts of policymakers from both the FDA and Congress concerned about the overuse, misuse, abuse, and addiction problems of popular and profitable psychopharmaceuticals, these products faced only relatively "small" and "mild" restrictions, among the "least strict" on offer.

The preceding history, though, helps shed light on alternative approaches to post-marketing regulation, particularly when considering proposals to strengthen the regulatory structure that were not adopted. Proposals from the 1940s and 1950s entailed on-the-ground policing and strict enforcement of prescribing, distribution, and even consumption requirements. Early 1950s legislation suggested allowing regulators to quickly move products into restrictive categories by adopting a precautionary principle, with a burden on the industry to prove safety rather than on the government to prove harm. Unlike the painstaking efforts to adjust marketing from the 1950 s through the 1980s, regulators might have been afforded greater latitude and more expeditious revisionary powers. Likewise, unlike the lengthy, delayed, and contested scheduling politics of the 1960 s and 1970s, regulators from science-focused agencies might have been granted more direct powers to create new schedules and put products on new or different schedules, without requiring collaboration with more political agencies and elected officials. As proposed in the $1960 \mathrm{~s}$ and $1970 \mathrm{~s}$, government communications to doctors about recommendations, warnings, and refutations of industry claims might have been more forceful and frequent, and greater control over quasi-advertisements like sponsored medical journals, conferences, and disease-awareness campaigns might have been pursued. Less confrontationally, proposals in the late 1970s and early 1980s sought direct regulator communication with consumers via easily understood patient package inserts. Likewise, as noted from the 1950 s through the 1980s, more comprehensive and more rapidly received post-marketing surveillance data might have been produced, collected, analyzed, and disseminated, as well as more formal postapproval studies of adverse events.

Reflecting the enduring character of both post-marketing regulatory weaknesses and plausible methods of addressing them, contemporary proposals largely mirror those from the earlier eras examined here. These proposals include the provision of clear and concise drug facts boxes to consumers, the regulation of disease awareness campaigns, the creation of national prescriber and prescription databases, the production of improved adverse event surveillance

Replacement Therapy in America (Baltimore, MD: Johns Hopkins University Press, 2007), 143-44; Richert, Conservatism, 61-63. 
data and post-marketing studies, greater governmental control over the type and manner of treatments given for particular conditions and circumstances, increased clinical trial data transparency, and the curtailment or elimination of direct-to-consumer advertising. Such proposals have elsewhere become policies, but they remain actively debated and contested in the contemporary United States.

\section{CONCLUSION}

Can American political institutions significantly constrain medical autonomy and strongly regulate healthcare marketplaces? Contrary to claims about the federal government's regulatory strength over American medicine, this article supports arguments about government's limitations. By examining a different evidence base, post-marketing pharmaceutical regulation, and elaborating on a pocket of weakness in an otherwise strong institution, these findings substantiate claims about the fundamental limits on policymakers' and regulators' abilities to reshape the provision and consumption of medical care.

Although the FDA is the "world's most powerful regulatory agency" and a paradigmatic case of state strength, its powers specifically evolved to concentrate at the drug approval stage. ${ }^{168}$ By contrast, its post-marketing influence over products after their approval emerged as a distant secondary concern, and this trade-off of pre-market regulatory strength and post-marketing regulatory weakness was locked in and entrenched with each major reform. The limited post-marketing regulatory capabilities of the FDA, Congress, and the White House, combined with the political incentives of regulators and elected officials, constrained policymakers from robustly restricting access to or disincentivizing the prescription and consumption of a range of popular and problematic tranquilizers, sedatives, and stimulants from the 1940s to the 1980s, in spite of their varied and repeated efforts to do so. ${ }^{169}$ As concerns about misuse, overuse, abuse, side effects, and addiction grew, demands for regulation increased, but the government could not keep pace. The government's halting and ineffective regulatory efforts yielded inaction, constrained action, and created policy drift, and the pocket of weakness in the pharmaceutical regulatory structure durably shifted authority over medical

168. Carpenter, Reputation and Power, 22.

169. While the direct counterfactual of no efforts at governmental intervention cannot be observed, and political institutions' efforts may have produced indirect effects, what can be observed through the extensive analysis undertaken here (aggregating evidence across cases, products, institutions, and eras) are the broader patterns and structure of a constrained politics of post-marketing regulation and a recurring set of weaknesses, difficulties, and minimal effects. practices away from government and toward private practitioners and consumers. ${ }^{170}$

These findings have theoretical implications for scholars of American political development and substantive implications for scholars of health politics and policy, and they provide insight into contemporary public health crises. These findings speak to three particular issues: debates about the strength and weakness of the American state and institutions; analyses of the transformation of mental health treatment and the politics of medicalization; and the contemporary opioid epidemic's emergence, likely trajectory, and circumscribed solution set.

\subsection{Pockets of Weakness and Institutional Accounts of Drift}

The study of political development principally emphasizes durable shifts in governing authority that result from government's growth. ${ }^{171}$ This research agenda has been tremendously productive, but it can also potentially limit lines of inquiry and scholars' understandings of political development to a particular set of cases. An analytic approach seeking and emphasizing the development of state strength might yield findings comprising an incomplete or nonrepresentative set of state and institutional capacities. Responding to earlier claims of state weakness, current attention to state strength may overcorrect, obscuring areas of weakness. As such, this emphasis on strength may merit a correction of its own, given that strength and weakness are both outcomes to be explained, with each deserving empirical and theoretical investigation.

By elaborating an account of a pocket of weakness in a strong institution, this analysis helps to shift attention from scholars' predominant focus on state strength, institutional growth, and thickening to other important sites of political development and policymaking. Like the pockets of expertise that developed in state legislatures, the concept of pockets of weakness can yield new analytic insights. ${ }^{172}$ This concept can help direct attention toward locating sites of political development that derive from inaction, drift, and governmental authority's diminishment. Locating pockets of weakness may serve to

170. Orren and Skowronek, The Search for American Political Development, 122; Hacker et al., "Drift and Conversion," 180-89; Sheingate, "Institutional Dynamics."

171. This approach stresses cases of positive growth and thickening that occur through revision, conversion, layering, intercurrence, path dependence, and entrepreneurship; institutional sites and important deployments of state strength; manifestations of surprising sources of state strength; sites of strong policy outcomes amid weak policies; and smaller policies and lower-level policymaking efforts with larger and higher-level effects. Sheingate, "Institutional Dynamics," 470. More generally, see Orren and Skowronek, The Search for American Political Development; Valelly et al., Oxford Handbook of American Political Development.

172. Burns et al., "Pockets of Expertise." 
draw out other instances and processes of negative political development beyond rare cases of retrenchment, particularly those in which the government's authority diminishes relative to the market and private actors. Emphasizing weakness may help recover a more complete set of cases of political development, possibly yielding more representative evidence bases and richer theoretical understandings of the state's capacities.

"Policy-focused analysis" of the regulatory state may provide especially fruitful evidence of pockets of weakness. $^{173}$ Here, a regulatory institution with a history of thickening, autonomous policymaking, large budget, and reputation for expertise in its primary gatekeeping role nonetheless exhibited an entrenched pocket of weakness in its post-marketing duties, one with important implications for structuring social outcomes. This variation in capacities within a single institution collapses the standard weak versus strong institution dichotomy, a complexity likely present in other regulatory institutions that have varying tasks, subunits, and capabilities.

Lastly, many accounts of drift emphasize policy interests rather than institutional structures, focusing on the particularistic interests that hold policies in place as social demands increase. ${ }^{174}$ Here, a weak institutional structure, the post-marketing pharmaceutical regulatory process, was "poorly equipped to grapple" with a range of "new or newly intensified social risks" from popular psychopharmaceuticals. Further, this entrenched pocket of weakness, when interacted with policymakers' and regulators' political incentives, limited its successful updating in the face of increasing risks, further decreasing its efficacy. By examining how a generalizable institutional structure, a pocket of weakness, can cause inaction and drift, an institution-focused account of drift may offer analytic tools for identifying other underexplored cases of drift and political development in which the government's authority diminishes.

\subsection{Mental Health and the Political Causes of Medicalization}

Accounts of the transformation of American psychiatry emphasize movements away from social and environmental toward biological and psychopharmacological

173. Herschel Nachlis, review of The Politics of Precaution: Regulating Health, Safety, and Environmental Risks in Europe and the United States, by David Vogel, Law and Politics Book Review 24, no. 3 (2014): 135-40; Marc Allen Eisner, Regulatory Politics in an Age of Polarization and Drift: Beyond Deregulation (New York: Routledge, 2017); Jacob S. Hacker and Paul Pierson, "After the 'Master Theory': Downs, Schattschneider, and the Rebirth of Policy-Focused Analysis," Perspectives on Politics 12, no. 3 (2014): 643-62; Daniel Carpenter, "Institutional Strangulation: Bureaucratic Politics and Financial Reform in the Obama Administration," Perspectives on Politics 8, no. 3 (2010): $825-46$.

174. Hacker, "Privatizing Risk"; Hacker et al., "Drift and Conversion." disease models and treatments. Some accounts suggest that these shifts may have produced suboptimal treatment, mistreatment, and overtreatment, and may have helped to cause medicalization. Private actors, especially the psychiatric profession and pharmaceutical firms, are held as central to causing these transformations, with government's role largely limited to de-institutionalization. ${ }^{175}$

This analysis demonstrates how political factors were important necessary conditions for the transformation of psychiatric treatment. The intercurrence of the pharmaceutical regulatory structure, policymakers' political incentives, and new medical products produced repeated regulatory efforts that could not substantially rein in controversial and problematic treatment practices. ${ }^{176}$ Consequently, the treatment of mild to moderate psychological health issues with pharmaceutical drugs proliferated. Like other social outcomes, the transformation and medicalization of American mental health has important and underappreciated political origins. ${ }^{177}$ Political institutions, over and above private actors, can play important roles in disease development, treatment, and medicalization.

Other areas of medical treatment and diagnosis, and future treatments and medical technologies, are also likely to exhibit such dynamics. ${ }^{178}$ As Daniel Carpenter notes, because of the growth of "new medical procedures and products, new diseases and

175. Horwitz, Creating Mental Illness; Frances, Saving Normal; Conrad, The Medicalization of Society; Joel Paris, Overdiagnosis in Psychiatry: How Modern Psychiatry Lost Its Way While Creating a Diagnosis for Almost All of Life's Misfortunes (New York: Oxford University Press, 2015); David Mechanic and David A. Rochefort, "Deinstitutionalization: An Appraisal of Reform," Annual Review of Sociology 16 (1990): 301-27.

176. This intercurrence of regulatory structure, political incentives, and therapeutics also plausibly contributed to a range of other potentially generalizable outcomes: the entrenchment of pharmaceutical norms of treatment for mild to moderate psychological health issues; the substantiation of a biological model of disease; support for the association between the problem of psychological distress and the solution of consumer products; the medicalization of potentially ordinary and common distresses; and the crowding out and attendant lack of development of other alternative treatment practices, cultural norms, and disease models. In a different vein, this interaction is also likely to yield product replacement patterns of substitution and exnovation that reintroduce old or create new problems. The cases of the partial substitutions from Valium to Xanax or hydrocodone to oxycodone represent instances where seemingly new but largely similar products reintroduced old problems, while the case of the partial shift from tranquilizers to antidepressants in the 1990s and 2000s represents a case of exnovation where new products thought to solve old problems yield new problems.

177. For example, see Frymer, Black and Blue, Deondra Rose, "The Public Policy Roots of Women's Increasing College Degree Attainment: The National Defense Education Act of 1958 and the Higher Education Act of 1965," Studies in American Political Development 30, no. 1 (2016): 62-93.

178. H. Gilbert Welch, Lisa M. Schwartz, and Steven Woloshin, Overdiagnosed: Making People Sick in the Pursuit of Health (Boston: Beacon Press, 2011). 
understandings of disease ... the manner in which governments, politicians, and administrators confront these problems and processes ... is a critical research agenda for health policy scholars for years to come." 199 Accordingly, an appreciation of the political causes of medicalization documented here can provide insights into related policy debates, including the mechanisms by which political institutions make certain treatments more or less likely. Particularly in other cases of widespread chronic illnesses like diabetes, obesity, and heart disease, and cases of subjective, psychological, and affective illnesses like mental illness and physical pain, all of which have complex causes and contested treatment modalities-along with newer issues of predisease, medical devices, lifestyle improvements, and genetic screening, selection, and modification-understanding the politics of medicalization will be increasingly essential for scholars, policymakers, and practitioners.

\subsection{The Opioid Epidemic and the Persistence of Medical Autonomy}

Lastly, while the parallels between this analysis and the opioid epidemic are certainly not exact, they share important features that help explain the epidemic's emergence, potential trajectory, and circumscribed solution set.

The opioid epidemic is perhaps the most pressing public health crisis in America today. ${ }^{180}$ In 2012, 259 million prescriptions were written for opioids; in 2015, 97.5 million Americans used and 12.5 million misused prescription opioids; and the 2 million Americans addicted to these products accounted for $\$ 80$ billion in economic costs. ${ }^{181}$ Drug overdoses killed at least 64,000 people in 2016; about two-thirds of these deaths involved opioids, and about one-third involved prescription opioids. ${ }^{182}$ In October 2017,

179. Daniel Carpenter, "Is Health Politics Different?" Annual Review of Political Science 15 (2012): 297. (2018).

180. James Nachtwey, “The Opioid Diaries," Time 191, no. 9

181. Arthur Hughes, Matthew R. Williams, Rachel N. Lipari, Jonaki Bose, Elizabeth A. P. Copello, and Larry Kroutil, "Prescription Drug Use and Misuse in the United States: Results from the 2015 National Survey on Drug Use and Health," in NSDUH Data Review, https://www.samhsa.gov/data/sites/default/files/NSDUHFFR2-2015/NSDUH-FFR2-2015.htm; American Society of Addiction Medicine, "Opioid Addiction: 2016 Facts and Figures," https://www. asam.org/docs/default-source/advocacy/opioid-addiction-diseasefacts-figures.pdf; Anne Schuchat, Debra Houry, and Gery Guy, "New Data on Opioid Use and Prescribing in the United States," Journal of the American Medical Association 318, no. 5 (2017): 425-26.

182. Josh Katz, "The First Count of Fentanyl Deaths in 2016: Up 540\% in Three Years," New York Times, September 2, 2017. These products have also contributed to what Anne Case and Angus Deaton have called "deaths of despair" and the declining labor force participation of prime working age males identified by Alan Krueger. See also Justin Fox, "Which Came First, the Opioids or the Despair?" Bloomberg View, September 11, 2017; Anne Case and Angus Deaton, "Mortality and Morbidity in the 21st Century," Brookings Papers on Economic Activity (2017): 397-
President Donald Trump declared that "this epidemic is a national health emergency." 183

Prominent accounts of the opioid epidemic's emergence emphasize the roles of private actors, including pharmaceutical firms, pain treatment advocates, medical doctors, and drug cartels. These factors are essential to explaining the epidemic, but political institutions also play important and underappreciated roles. The post-marketing regulatory structure, and policymakers' and regulators' inabilities and unwillingness to "restrict [opioids'] use somehow," helped the crisis emerge and expand.

The epidemic's emergence, potential trajectory, and circumscribed solution set follow from the interaction of the post-marketing regulatory structure and policymakers' political incentives described here and reflect many of the dynamics present in these earlier eras.

The relative ineffectiveness of information-management-based approaches to addressing the opioid epidemic has manifested itself in various ways: inaccurate and misleading labels that have been difficult to correct; extensive advertising campaigns suggesting expansive and off-label uses that are hard to rein in; an inability to regulate disease awareness campaigns, specialized conferences, and specialized journals produced by therapeutic firms; delayed, lacking, and inconclusive post-marketing risk data from limited pharmacovigilance systems whose robust provision might animate and substantiate regulation; and minimally effective returns on related informational approaches like providing overprescription data to doctors or tracking prescriptions in databases.

The difficulties of bureaucratic policymaking, particularly when interacted with the political incentives of regulators and policymakers and the efforts of mobilized private groups opposing regulation, have

443; Christopher J. Ruhm, "Deaths of Despair or Drug Problems?" NBER Working Paper 24188 (2018); Anne Case and Angus Deaton, "Deaths of Despair Redux: A Response to Christopher Ruhm" (January 8, 2018), https://www.princeton.edu/ accase/down loads/Case_and_Deaton_Comment_on_CJRuhm_Jan_2018.pdf. Though prescribing has declined between 10 to 20 percent from the 2012 highs in the most recent data, opioid prescribing rates are still over three times what they were in 1999. In light of these figures and trends, the director of the Centers for Disease Control, Thomas R. Frieden, argued in mid-2016 that "it's a tide turning, but you have to put it into perspective" because "[the current level of prescribing] still leaves us in very dangerous waters." Abby Goodnough and Sabrina Tavernise, "Opioid Prescriptions Drop for First Time in Two Decades," New York Times, May 20, 2016. Frieden's successor, Anne Schuchat, noted in 2017 that current levels were still enough for "every American [to] be medicated around the clock for three weeks." Rob Stein, "Opioid Prescriptions Falling but Remain Too High, CDC says," NPR, July 6, 2017. More than a third of overdoses and deaths involving opioids also involve the types of non-opioid pharmaceuticals examined here, including tranquilizers, sedatives, and stimulants.

183. Dan Merica, "Trump Declares Opioid Epidemic a National Public Health Emergency," CNN, October 26, 2017. 
contributed to the opioid epidemic through lengthy, contested, and delayed efforts to scientifically reassess products; similarly laborious, contested, piecemeal, and delayed drug re-categorization efforts and reductions to production quotas; contested and delayed production of nonbinding prescribing guidelines; and agencies that do not want costly and lengthy legal challenges to work not central to their missions that therefore avoid intensive enforcement efforts. These factors have also interacted to constrain law enforcement-based approaches to addressing the opioid epidemic, including regulators' and policymakers' inability and unwillingness to police and shut down excessive prescribers and distributors beyond the most egregious "pill mills" and a reluctance to commit more resources to more broadly police problematic prescribing, distribution, sale, and consumption in communities throughout the country.

The structure and entrenchment of the inherited regulatory regime have also constrained responses to the opioid epidemic, as has the interaction of this weak and entrenched regulatory structure with policymakers' political incentives. Because new regulatory efforts draw on and are layered atop existing policies, there has been little effort to create new restrictive schemes within a long-standing approach to drug categorization. Further, the political incentives of regulators and legislators have interacted with this inherited regulatory structure to additionally limit strong regulation. Accordingly, policy discussions of the opioid epidemic feature significant blame avoidance and blame shifting, with Congress blaming agencies, agencies blaming Congress, and both blaming private actors. At the same time, policymakers have often focused on easy-to-attack and higher-profile illegal drugs like heroin and illegally imported fentanyl. And throughout these debates, well-resourced and mobilized opponents to regulation like physicians and producers are able to exploit pivotal actors, chokepoints, and veto players in regulatory and legislative institutions. ${ }^{184}$

184. Sam Quinones, Dreamland: The True Tale of America's Opiate Epidemic (New York: Bloomsbury, 2016); Patrick Radden Keefe, "The Family That Built an Empire of Pain," New Yorker, October 30, 2017; Scott Higham and Lenny Bernstein, "The Drug Industry's Triumph over the DEA," Washington Post, October 15, 2017; Lenny Bernstein and Scott Higham, "The Government's Struggle to Hold Opioid Manufacturers Accountable," Washington Post, April 2, 2017; Sabrina Tavernise, "Dr. Robert Califf Wins Senate Confirmation to Run F.D.A.," New York Times, February 24, 2016; "Congress Has Not Matched Rhetoric with Action on Opioid Crisis," CQ Magazine, April 18, 2016; Jayne O'Donnell, "FDA Chief Supports Opioid Prescription Limits, Regrets Agency's Prior Inaction," USA Today, October 23, 2017; German Lopez, "Want to Understand How Big Pharma Helped Create the Opioid Epidemic? Read This Report." Vox, September 6, 2017; Art Van Zee, "The Promotion and Marketing of OxyContin: Commercial Triumph, Public Health Tragedy," American Journal of Public Health 99, no. 2 (2009): 221-27; Nicholas Kristoff, “'Drug Dealers in Lab Coats,” New York Times, October 18,
These recurrent constraints on federal regulation help explain why leading approaches to combatting the opioid epidemic have emphasized other tools. Because policymakers seek to benefit from addressing the epidemic by criticizing firms, doctors, and dealers while avoiding the difficulty of infringing on medical and consumer autonomy, policymakers have often pursued nonregulatory solutions that, while easier to achieve, have not as yet proven particularly effective. The most discussed and well-funded tools offered to combat the contemporary crisis are not primarily regulatory, but rather approaches emphasizing psychotherapeutic counseling, support groups, medication-assisted addiction treatments, overdose-reversing drugs, doctor and patient education, public-awareness campaigns, state-level prescription and prescriber monitoring programs, state-level prescribing guidelines, local and statelevel lawsuits, and nonaddictive pain treatments. ${ }^{185}$

While these approaches are laudable and some have shown noteworthy signs of success, they are also limited and, like the earlier regulatory efforts examined here, "unlikely to be a terribly effective strategy for altering physician behavior" and unlikely to "undo the damage already done." But in a constrained regulatory environment, mostly nonregulatory tools are potentially among the more plausible routes to achievable marginal improvements. Larger solutions, however, may eventually be found outside of political institutions, including firms' eventual loss of patent protections for popular products, exnovation and the adoption of new treatment practices, and, perhaps most importantly, culture, preference, and behavior changes among doctors, producers, distributors, consumers, and the public at large. ${ }^{186}$

2017; Bridget M. Kuehn, "DEA Tightens Restrictions on Hydrocodone Combination Products," Health Affairs 312, no. 12 (2014): 1185; Adam Sacarny, David Yokum, Amy Finkelstein, and Shantanu Agrawal, "Medicare Letters to Curb Overprescribing of Controlled Substances Had No Discernable Effect on Providers," Health Affairs 35, no. 3 (2016): 471-79.

185. G. Caleb Alexander, S. Frattaroli, and A. C. Gielen, eds., The Prescription Opioid Epidemic: An Evidence-Based Approach (Baltimore, MD: Johns Hopkins University School of Public Health, 2015); Kelly Murphy, Melinda Becker, Jeff Locke, Chelsea Kelleher, Jeff McLeod, and Frederick Isasi, Finding Solutions to the Prescription Opioid and Heroin Crisis: A Road Map for States (Washington, DC: National Governors Association Center for Best Practices, 2016); National Academies of Science, Engineering, and Medicine, Pain Management and the Opioid Epidemic: Balancing Societal and Individual Benefits and Risks of Prescription Opioid Use (Washington, DC: The National Academies Press, 2017); National Academy of Medicine, First Do No Harm: Marshaling Clinician Leadership to Counter the Opioid Epidemic (Washington, DC: National Academy of Medicine, 2017); "America's 8-Step Program for Opioid Addiction," editorial, New York Times, September 30, 2017; German Lopez, "I Looked for a State That's Taken the Opioid Epidemic Seriously. I Found Vermont." Vox, October 31, 2017.

186. As Senator Claire McCaskill has recently argued, political actors can indirectly affect nonregulatory cultural processes: "Sometimes you can even make a difference without legislation, and just shine the bright light of public attention on problems. 
Moving beyond the opioid epidemic and more broadly, in an era when political leaders are calling for the "deconstruction of the administrative state," recognizing constraints on the country's most powerful regulatory and political institutions even in the face of its largest public health crisis can help counter critiques of purportedly excessive regulation. ${ }^{187}$ Both the contemporary opioid epidemic and earlier efforts to regulate popular psychopharmaceuticals demonstrate not just the importance of a pocket of regulatory weakness, but also some of the negative consequences and the enduring persistence of medical autonomy.
... It makes a difference." German Lopez, "Sen. Claire McCaskill on the Opioid Epidemic: Pharma 'Ought to Begin Looking over Their Shoulder," Vox, October 11, 2017. Therapeutic historian James Harvey Young, however, suggests that based on studying centuries of American patent medicines, that any cultural changes curtailing the selling and consumption of therapeutics are always likely to be limited. James Harvey Young, The Toadstool Millionaires: A Social History of Patent Medicines in America before Federal Regulation (Princeton, NJ: Princeton University Press, 1961), 253.
187. Philip Rucker and Robert Costa, "Bannon Vows a Daily Fight for 'Deconstruction of the Administrative State," Washington Post, February 23, 2017. 